Article

\title{
Experimental Investigation and Multi-Response Optimization of Machinability of AA5005H34 Using Composite Desirability Coupled with PCA
}

\author{
Mohsin Iqbal Qazi ${ }^{1}$, Muhammad Abas ${ }^{2, *}$, Razaullah Khan ${ }^{3}$, Waqas Saleem ${ }^{4}$, Catalin Iulian Pruncu ${ }^{5,6, *}$ \\ and Muhammad Omair ${ }^{1}$
}

Citation: Qazi, M.I.; Abas, M.; Khan,

R.; Saleem, W.; Pruncu, C.I.

Experimental Investigation and Multi Response Optimization of Machinability of AA5005H34 Using Composite Desirability Coupled with PCA. Metals 2021, 11, 235. https://doi.org/10.3390/met11020235

Academic Editor: Tadeusz Mikolajczyk, Danil Yurievich Pimenov and Munish Kumar Gupta Received: 10 January 2021

Accepted: 25 January 2021

Published: 31 January 202

Publisher's Note: MDPI stays neutral with regard to jurisdictional claims in published maps and institutional affiliations.

Copyright: (C) 2021 by the authors. Licensee MDPI, Basel, Switzerland. This article is an open access article distributed under the terms and conditions of the Creative Commons Attribution (CC BY) license (http://creativecommons.org/licenses/by/4.0/).
1 Department of Industrial Engineering, Jalozai Campus, University of Engineering and Technology Peshawar, Nowshera 24240, Pakistan; mohsin@uetpeshawar.edu.pk (M.I.Q.); momair@uetpeshawar.edu.pk (M.O.)

2 Department of Industrial Engineering, University of Engineering and Technology, Peshawar 25120, Pakistan

3 Department of Mechanical Engineering Technology, University of Technology, Nowshera 24100, Pakistan; razaullah@uotnowshera.edu.pk

4 Department of Mechanical and Manufacturing Engineering, Institute of Technology, F91 YW50 Sligo, Ireland; waqas95@yahoo.com

5 Design, Manufacturing \& Engineering Management, University of Strathclyde, Glasgow G1 1XJ, Scotland, UK

6 Mechanical Engineering, Imperial College London, Exhibition Road, South Kensington, London SW7 2AZ, UK

* Correspondence: muhammadabas@uetpeshawar.edu.pk (M.A.); c.pruncu@imperial.ac.uk or catalin.pruncu@strath.ac.uk (C.I.P.)

Abstract: Minimum quantity lubricant (MQL) is an advanced technique in machining to achieve sustainability, productivity, higher precision, economic benefits, and a reduction in carbon footprints. The present research work aims to investigate the effect of the cutting process parameters of the end milling of AA5005H34 material under dry and MQL cutting environments. The key performance indicators of machining include the surface roughness profile, the material removal rate, and tool wear. Surface roughness parameters are measured with the help of the Mitutoyo surface roughness tester, and the cutting tool wear is measured according to the ISO 8688-2:1989 standard using a scanning electron microscope (SEM). Sixteen experiments are designed based on the Taguchi orthogonal array mixture design. Single responses are optimized based on signal to noise ratios, while for multi-response optimization composite desirability function coupled with principal component analysis is applied. Analysis of variance (ANOVA) results revealed that the feed rate followed by spindle speed, axial depth of the cut, width of the cut, and cutting environment are the most significant factors contributing to the surface roughness profile, material removal rate, and tool wear. The optimized parameters are obtained as cutting speed of $3000 \mathrm{rev} / \mathrm{min}$, feed rate of $350 \mathrm{~mm} / \mathrm{min}$, axial depth of cut of $2 \mathrm{~mm}$, and width of cut of $6 \mathrm{~mm}$ under an MQL environment.

Keywords: milling; minimum lubricant quantity (MQL); aluminum alloy; Taguchi orthogonal array; signal to noise ratios; analysis of variance; principal component analysis (PCA); composite desirability method

\section{Introduction}

Green manufacturing is a leading trend in sustainable production to produce machined jobs with the aim of substituting environment polluting processes. The objective can be best achieved by adopting dry machining [1]. Dry machining is a sustainable method that diminishes the problems associated with the machining of commercially used alloys such as steel, aluminum, and cast iron [2]. Owing to the demands of future machining, such as cost, health concerns, and mitigating ecological issues, dry machining 
is an optimal choice to resolve these issues [3]. It is widely employed as a reference standard to measure cutting fluids' effectiveness and the interrelationships among tool wear, product quality, and temperature [4]. However, machining aluminum under dry conditions is extremely difficult due to the higher chemical affinity [5]. This can be controlled by numerous cooling techniques such as flooded coolant [6], oil-water [7], cryogenic cooling (carbon dioxide, liquid nitrogen) [8], minimum quantity lubricant (MQL) [6], and nanofluids [9]. MQL is a novel cooling technique in which coolant is sprayed at the toolsurface interface with the aid of compressed air at a controlled pressure [10]. MQL reduces the total manufacturing cost as well helping to obtain vital and desirous machining quality attributes, such as excellent surface finish i.e., average roughness $(\mathrm{Ra})$, root mean square (Rq), depth of peaks and valleys on the surface (Rz) [11], greater tool life [12], higher material removal rate [13], and enhanced dimensional accuracy [10]. In the MQL strategy, nearly $70 \%$ of heat is carried away by chips [14]. The MQL method is the most suitable, as it successfully satisfies the pre-requisites of sustainable eco-friendly machining [15].

In milling, the material removal rate (MRR) has vital importance, as it significantly affects the production rate/productivity, energy consumption, cutting forces, and tool life [16]. Surface roughness (SR) is an important criterion and a crucial indicator in achieving the desired quality and performance of the machined product. Hence, SR must be controlled during machining to obtain the lowest possible values [17]. Abhang et al. [18] demonstrated that SR governs the fatigue strength, friction properties, wear, and corrosion resistance of machined surfaces. Tool life is the actual service length for which a tool performs satisfactorily, provides a good surface finish, and provides a reasonable MRR before replacement. A longer tool life reduces cost and improves productivity [19]. The appropriate selection of critical parameters, especially cutting speed, feed rate, depth of cut, and lubrication method, significantly impacts the job quality and process efficiency [20]. Vegetable oil [6,21], esters, and nanofluids $[6,9,21]$ have substituted poisonous petroleum-based oils due to their eco-friendly, biodegradable, non-toxic, and renewable nature.

Jebaraj et al. [22] studied the influence of the process parameters - namely feed rate, spindle speed, and cooling environment (wet and cryogenic $\mathrm{CO}_{2}$ and $\mathrm{LN}_{2}$ ) - in the milling of Al6082-T6 alloy using an uncoated carbide insert. The output responses were average surface roughness, feed force, normal force, axial force, and cutting temperature. TOPSIS (The technique for order of preference by similarity to ideal solution) was applied to optimize the multi-responses. The analysis of variance (ANOVA) results showed that cooling environment has a significant effect on all considered responses, followed by feed rate and spindle speed. The optimal parameters obtained were wet cooling conditions, cutting speed of $125 \mathrm{~m} / \mathrm{min}$, and feed rate of $0.02 \mathrm{~mm} /$ tooth. Raju et al. [23] developed a model for surface roughness and optimized the cutting parameters of aluminum alloy 6061 with carbide and high-speed steel (HSS) in end milling under dry and wet environments. The ANOVA results showed that for both dry and wet environments, feed rate followed by spindle speed has a dominant effect on surface roughness; however, the depth of cut was found to be the least contributing factor. A genetic algorithm (GA) was employed to achieve optimum machining conditions. For the HSS tool without the use of a coolant, the optimized parameters are a cutting speed of $1488 \mathrm{rpm}$, a feed rate of $200 \mathrm{~m} / \mathrm{min}$, a depth of cut of $1.5 \mathrm{~mm}$; however, with the use of a coolant, they are $1465 \mathrm{rpm}, 200 \mathrm{~m} / \mathrm{min}$, and $1.5 \mathrm{~mm}$. For a coated carbide tool without the use of a coolant, they are $1500 \mathrm{rpm}, 200$ $\mathrm{m} / \mathrm{min}$, and $1.5 \mathrm{~mm}$, while for with the use of a coolant they are $1477 \mathrm{rpm}, 200 \mathrm{~m} / \mathrm{min}$, and $1.5 \mathrm{~mm}$.

Elsen et al. [24] optimized the end milling process parameter (spindle speed, feed rate, and depth of cut) for a stir-casted alumina-reinforced aluminum metal matrix composite using response surface methodology (RSM) under a dry environment. The performance parameters investigated were average surface roughness and machining time. The ANOVA results revealed that cutting speed and depth of cut have a significant effect on surface roughness, while for machining time the cutting speed and feed rate were the most 
influencing parameters. Minimum surface roughness (1.514 micro) and machining time (18.4 s) were obtained at optimized parameters - i.e., higher cutting speed of $1750 \mathrm{rev} / \mathrm{min}$, lower feed rate of $0.4 \mathrm{~mm} / \mathrm{rev}$, and depth of cut at $0.2 \mathrm{~mm}$.

Kumar et al. [25] studied the high-speed milling of BSL 168 aluminum composites under wet conditions. The Box Behnkn array is designed for experimental runs comprised of four factors-i.e., spindle speed, depth of cut, feed rate, and coolant. The output responses were surface roughness and material removal rate, while the cutting operation was performed on the flat end mill cutter. Responses are simultaneously optimized based on composite desirability function. ANOVA results revealed that the depth of cut has a significant effect on the surface roughness and material removal rate, followed by spindle speed, feed rate, and coolant. Tsao [26] applied the Grey-Taguchi method to optimize the end milling parameters of aluminum alloy A6061P-T651. The factors considered were coating type, helix angle, primary relief angle, cutter diameter, depth of cutting, width of cut, feed rate, and spindle speed. The type of cutter used was an end mill tungsten carbide and the responses were flank wear and surface roughness. The ANOVA results showed that the most influencing parameters affecting flank wear were cutter diameter followed by coating type, helix angle, relief angle, depth of cutting, and width of cutting. For surface roughness, feed rate followed by cutter diameter and coating were found to be significant.

Lmalghan et al. [27] optimized the face milling parameters of aluminum alloy AA6061 using the Response Surface Methodology and the Particle Swarm Optimization technique under dry conditions. Experimental runs are planned based on the central composite design (i.e., 20). The ANOVA results showed that the spindle speed was the most dominant factor affecting all responses, followed by feed rate and depth of cut. The optimized parameters obtained based on PSO to achieve a minimum surface roughness $(0.494$ $\mu \mathrm{m})$, cutting force $(166.85 \mathrm{~N})$, and power consumption $(0.265 \mathrm{~kW})$ were spindle speed of $3000 \mathrm{rpm}$, feed rate of $500 \mathrm{~mm} / \mathrm{min}$, and depth of cut of $3 \mathrm{~mm}$. Rajeswari and Amirthagadeswaran [28] investigated the machinability characteristics and optimization of the end milling of aluminum composites (7075 metal matrix) using RSM-based grey relational analysis. The machining performance to be studied were surface roughness, material removal rate, tool life, and power consumption. It was found that the spindle speed and weight percentage of $\mathrm{SiC}$ were the most significant parameters for all responses. The optimized parameters to achieve a higher material removal rate, low cutting force, minimum surface roughness, and lower tool wear were spindle speed of $1000 \mathrm{rpm}$, feed rate of $0.03 \mathrm{~mm} / \mathrm{rev}$, depth of cut of $1 \mathrm{~mm}$, and $5 \%$ of SiC. Tosun and Pihtili [29] optimized the cutting process parameters (feed rate, spindle speed, tool material, and cooling technique) of the face milling of 7075 aluminum alloy using grey relational analysis (GRA). The responses considered were surface roughness and material removal rate. They concluded that feed rate is one of the dominant factors among the considered factors that affect the surface roughness and material removal rate in milling, followed by cutting speed, tool material, and cooling technique. The optimized parameters obtained are the cooling environment of a flood coolant, the tool material of a carbide tool, a spindle speed of $1330 \mathrm{rpm}$, and a feed rate of $80 \mathrm{~mm} / \mathrm{min}$.

The industry's desire to improve quality, productivity, efficiency, and cost reduction is strongly associated with the proper selection of cutting parameters at optimal levels [29]. The utmost objective of the machining sector is a higher MRR, admirable quality surface finish, higher tool life, and cost reduction. However, achieving this objective is quite difficult, as finding the optimal combination that simultaneously improves surface finish, MRR, and diminishing tool wear rate requires the application of complex statistical methods and resource consumption. High feed rate, cutting speed, and depth of cut promote a higher MRR; however, this combination also causes intense heat production at the cutting zone that significantly deteriorates the dimensional accuracy, tool life, and surface finish [21,29]. Abas et al. [30] carried out experimental and statistical studies to optimize the cutting parameters to minimize cutting forces and shape deviations in Al6026-T9. The machining was performed with virgin olive oil and an uncoated tungsten carbide tool. 
The experimental runs were planned based on Taguchi mixture orthogonal array design L16. Their study concluded that feed rate was the most important factor for all components of cutting forces and shape deviation. Waseem et al. [31] applied multi-response optimization to predict the tensile creep behavior of parts produced by means of additive manufacturing. The work was accomplished using a categorical response surface methodology. Their research work revealed that the most influencing factors for creep rate were layer height, infill percentage, and infill patterns. In statistical evaluation and prediction, one of the promising techniques is structural equation modeling (SEM). For example, Kamal et al. [32] used SEM to perform a quantitative analysis of the sustainable use of construction materials. Their results revealed that the components of supply chain integration were statistically significant in terms of the construction industry performance.

Besides aluminum alloys, researchers have also explored the optimum surface roughness parameters of hard-to-cut materials under different cutting conditions. For instance, Markopoulos et al. [33] investigated the slot milling of hardened AISI O1 steel alloy and evaluated the influence of cutting feed, speed, and depth of cut on the surface roughness. Their work considered the sustainability assessment criterion for determining stable characteristics for the eco-benign machining of hardened steel. Pimenov et al. [34] studied the surface quality and energy consumption of AISI 1045 steel during face milling in terms of costs and material removal rate. Abbas et al. [35] reported a detailed study on optimizing the milling process parameters of high-strength grade- $\mathrm{H}$ steel by employing artificial neural networks and the Edgeworth-Pareto method. Muhammad et al. [36] performed experimental tests and statistical evaluations for the micro-milling of Inconel 718 to evaluate the effect of the tool coating and cutting parameters on surface roughness. The ANOVA results predicted that the coating was a significant parameter for both burr formation and surface roughness. Sen et al. [37] investigated the wire electrical discharge machining (WEDM) process parameters of an Inconel-800 superalloy. They applied a trapezoidal interval type-2 fuzzy number integrated analytical hierarchy process-based additive ratio assessment method. They evaluated the obtained results with existing multi-criteria decision-making methods.

A local manufacturing sector is facing issues in controlling and optimizing machining parameters to achieve the desired surface finish quality, higher productivity (in terms of material removal rate), and low setup cost (in terms of low tool wear). Currently, the setting of cutting parameters is attained by commonly employed traditional methodsi.e., trial and error-which is cumbersome, error-based, and time-consuming. One of the most reliable approaches to determine the optimum cutting parameters is numerical simulation. Numerous reliable studies have shown that numerically predicted outcomes closely conform with the experimental results. For instance, Waqas et al. [38] performed a numerical modeling and analysis of Ti6Al4V alloy using Abaqus/Explicit and predicted the cutting reaction forces and shearing zone temperature. The predicted results were close to the experimental ones. A general summary of the related published studies is presented in Table 1 . The summary outlines the cutting conditions used in any particular machining process, the research approaches adopted, and the machining characteristics studied. 
Table 1. A general summary of related published studies (cutting conditions and machining performance characteristics).

\begin{tabular}{|c|c|c|c|}
\hline & $\begin{array}{l}\text { Machining Method/Cutting } \\
\text { Conditions }\end{array}$ & Material and Characteristics Studied & Investigation Approach \\
\hline [2] & Different cooling-lubrication & Hardened steel, machining parameters & Experimental invertigation \\
\hline [5] & Micro end-milling & Tool wear & FEA, numerical investigation \\
\hline [7] & $\begin{array}{l}\text { Spray cutting fluids, high speed mill- } \\
\text { ing }\end{array}$ & Machining characteristics & $\begin{array}{l}\text { Experimental and numerical inves- } \\
\text { tigation }\end{array}$ \\
\hline [8] & Cryogenic N2 assisted turning & Ti-6Al-4V, tool life cycle assessment & Multi-objective optimization \\
\hline [10] & Face milling, $\mathrm{Al}_{2} \mathrm{O}_{3}$ based $\mathrm{MQL}$ & D2 Steel & A comparative study \\
\hline [11] & Biodegradable oil-based MQL & Hardened steel, machining characteristics & Experimental invertigation \\
\hline [13] & $\begin{array}{l}\text { Nanofluid SQCL assisted face mill- } \\
\text { ing }\end{array}$ & Aluminum, energy consumption, surface quality & Multi-objective optimization \\
\hline [14] & MQL grinding, vegetable oils & $\begin{array}{c}\text { Nickel-base alloy, grinding temperature, energy } \\
\text { ratio coefficient }\end{array}$ & Experimental invertigation \\
\hline [16] & Milling & MRR, computational accuracy & Voxel-based analysis \\
\hline [17] & Dry, MQL milling & AISI 4140, machining characteristics & Taguchi design, ANOVA \\
\hline [18] & Milling & En-31 steel alloy, machining characteristics & Multi performance optimization \\
\hline $\begin{array}{c}\text { [9], } \\
{[19-} \\
21]\end{array}$ & Vegetable oil-bas & Alum & $\operatorname{Re}$ \\
\hline [24] & End milling & Aluminum metal matrix composite & RSM \\
\hline [26] & Milling parameters & Aluminum machining characteristics & Grey-Taguchi method \\
\hline [27] & End milling & AA6061, machining parameters & RSM, particle swarm \\
\hline [28] & Milling & Aluminum composites, machining parameters & RSM based grey relational analysis \\
\hline [29] & MQL milling & $7075 \mathrm{Al}$ alloy, machining parameters & Grey relational analysis \\
\hline [30] & Turning under MQL & Al6026-T9, cutting forces & Statistical evaluation \\
\hline [33] & Slot milling & AISI O1, machining parameters, surface quality & Regression analysis \\
\hline [34] & Face milling & AISI 1045, surface quality, MRR & Multi-layer regression analysis \\
\hline [35] & CNC Face milling & high-strength grade-H steel, cutting conditions & Artificial Neural Network (ANN) \\
\hline [36] & Micro-milling & Inconel 718, cutting parameters, surface quality & Statistical evaluation \\
\hline [38] & Milling under dry & Ti6Al4V alloy, cutting forces and temperature & Numerical analysis \\
\hline [39] & MQL-assisted turning process & 6026-T9, machining parameters & Experimental invertigation \\
\hline [40] & Dry CNC turning & $7075 \mathrm{Al}$ composite, machining parameters & Experimental investigation \\
\hline [41] & Helical milling & $\mathrm{Al} 7075$ cutting forces & Multivariate optimization \\
\hline [42] & Dry end milling & $\begin{array}{l}\text { Weighted principal component analysis, Taguchi's } \\
\text { signal-to-noise ratio }\end{array}$ & Multi-objective optimization \\
\hline [43] & Milling & Multiple response characteristics & ational approach \\
\hline [44] & End milling & $\begin{array}{l}\mathrm{Al} / \mathrm{SiCp} \text { metal matrix composite, surface rough- } \\
\text { ness }\end{array}$ & Predictive modeling \\
\hline [45] & Milling & Aluminum, machining parameters & Taguchi-Grey approach \\
\hline$[46,47]$ & Milling, nano-fluids & Tool wear, residual stress & Experimental invertigation \\
\hline
\end{tabular}

This article aims to identify, evaluate, and optimize the end milling cutting parameters on quality responses for AA5005H34 by employing a hybrid approach of principal component analysis (PCA) coupled with the composite desirability function (CDF). Sixteen experiments were conducted based on the L16 Taguchi orthogonal array (OA) mixture design to assess the optimal cutting parameter combination for quality responsesnamely, surface roughness profile, material removal rate, and flank wear $\left(\mathrm{V}_{\mathrm{b}}\right)$. It is reported regarding the authors' best knowledge and literature survey that the optimization of the end milling machining of AA5005H34 has not been reported yet. Therefore, this research represents a worthwhile contribution in fulfilling the said gap.

Initially, this research presents materials and methods for selecting machining parameters. This is followed by the Taguchi orthogonal array (OA) mixture design. Then, the statistical analysis and optimization of experimental results are analyzed by the 
Taguchi SN ratios. In the last section, the achievement of multi-optimization and its validation through confirmatory experiments is explained.

\section{Applications of Research Work}

It is believed that this research is the first reported study on the optimization of the end milling machining of AA5005H34. The authors could not find published articles on this study in renowned databases by applying different search strings and terms with different Boolean operators. Therefore, this study would bridge the gap in this research domain in the form of a worthwhile contribution. This research is beneficial for researchers in advanced machining as it employs MQL cutting conditions. The presented study proves that MQL produces promising results due to it offering a higher productivity, improved surface texture, and extended tool life as compared to dry machining. The experimental and statistically grounded research findings provide a comprehensive guide to the manufacturing sector for improving the machinability of AA5005-H34.

\section{Materials and Methods}

\subsection{Material}

Aluminum alloy 5005 H34 (BOZHONG METAL GROUP, Shanghai, China)was machined using a computer numerical control (CNC) end milling machine, LG-500 HARTFORD (Hartford machining centers, Shanghai, China). These alloys are widely used because of their excellent atmospheric corrosion resistance capabilities, good strength, and good weldability. The most common applications are in high strength foil, architectural applications, and general sheet metal work [48]. Its chemical compositions are shown in Table 2.

Table 2. Chemical composition of AA5005-H34.

\begin{tabular}{cccccccccc}
\hline Element & Al & Si & Mg & Fe & Cr & $\mathbf{C u}$ & Mn & Zn & Others \\
\hline \% by weight & 97.63 & 0.30 & 1.10 & 0.07 & 0.10 & 0.20 & 0.20 & 0.25 & 0.15 \\
\hline
\end{tabular}

\subsection{Cutting Process Parameters}

The selection of input cutting process parameters and levels was carried out through a literature survey, manufacturer recommendations, machining experts, and machine capabilities. Six influential parameters are taken in this research work-i.e., spindle speed $(S)$, feed rate $(F)$, depth of cut $(D)$, width of cut $(W)$, and cutting conditions (namely, dry and MQL).

Figure 1 shows the experimental setup, illustrating the machining of aluminum alloy and also the cutting kinematics with the MQL setup. The selected parameter units and levels are depicted in Table 3. The lubricant used was olive oil. It was proven to be effective in the end milling of AISI 304 steel [49], the turning of 40 HRC hardened steel [11], the turning of AISI 1060 steel [50], and the turning of aluminum Al 6026-T9 [37]. Olive oil is also preferred because it is biodegradable and has environmentally friendly [11] characteristics. Its viscosity is $84 \mathrm{cp}$ at $20^{\circ} \mathrm{C}$, its specific heat capacity is $1.97 \mathrm{~J} /\left(\mathrm{g}{ }^{\circ} \mathrm{C}\right)$, its specific gravity is 0.911 at $20^{\circ} \mathrm{C}$, and its boiling point is $700{ }^{\circ} \mathrm{C}$. 


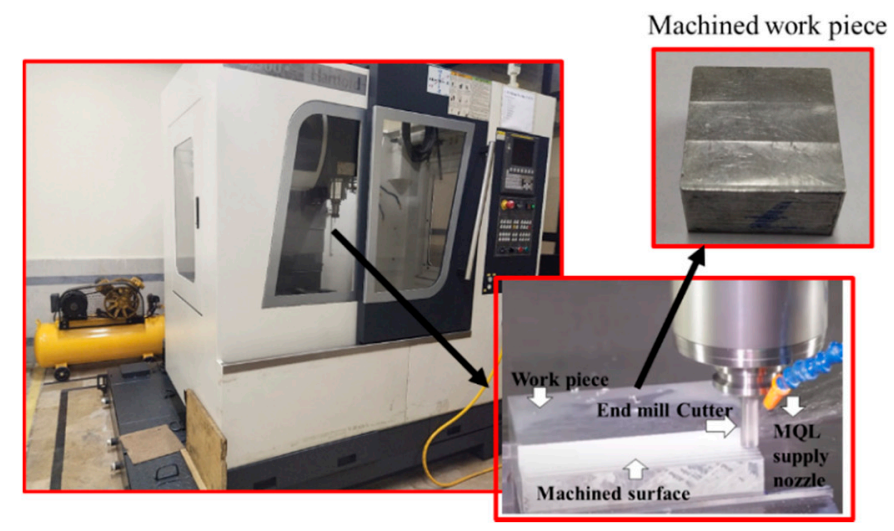

(a)

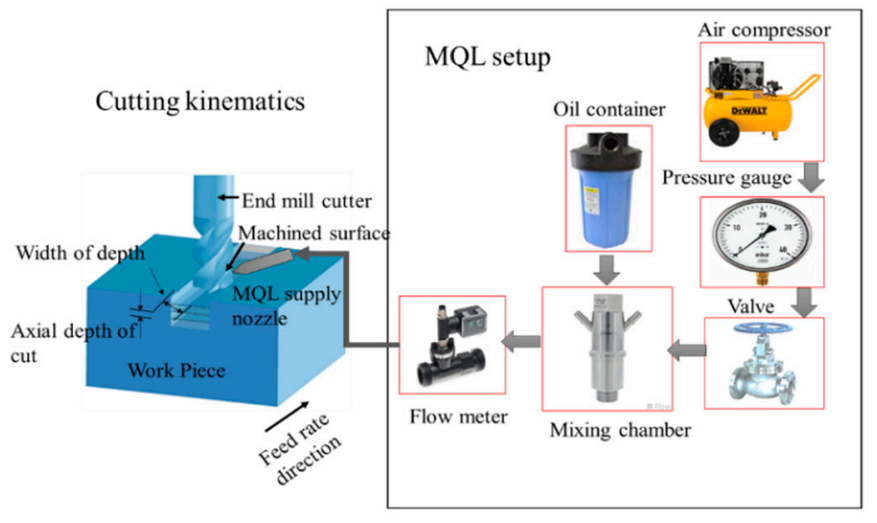

(b)

Figure 1. Experimental setup: (a) end milling of aluminum alloy, (b) schematic of cutting kinematics and MQL setup.

Table 3. Selected machining parameters and levels.

\begin{tabular}{ccccccc}
\hline \multirow{2}{*}{ Factors } & \multirow{2}{*}{ Symbols } & \multirow{2}{*}{ Units } & $\mathbf{1}$ & $\mathbf{2}$ & $\mathbf{3}$ & $\mathbf{4}$ \\
\hline Spindle speed & $\mathrm{S}$ & $\mathrm{rev} / \mathrm{min}$ & 1000 & 2000 & 3000 & 4000 \\
Feed rate & $\mathrm{F}$ & $\mathrm{mm} / \mathrm{min}$ & 250 & 350 & 450 & 550 \\
Axial depth of cut & $\mathrm{D}$ & $\mathrm{mm}$ & 1 & 1.5 & 2 & 2.5 \\
Width of cut & $\mathrm{W}$ & $\mathrm{mm}$ & 2 & 6 & 10 & 14 \\
Cutting conditions & $\mathrm{C}$ & - & Dry & $\mathrm{MQL}$ & - & - \\
\hline
\end{tabular}

\subsection{Responses Variables}

The predominant quality characteristics that are considered in this research work are the surface roughness profile, the material removal rate, and tool wear. Surface roughness portrays the geometry and texture of the machined surface and greatly influences manufacturing costs. The three main surface roughness parameters depicted in standards are average roughness height $(\mathrm{Ra})$, root mean square height $(\mathrm{Rq})$, and average of maximum roughness $(\mathrm{Rz})$ [39]. They were measured at three different locations and measurements were repeated twice at each location on the machined surface with the help of a Mitutoyo surface roughness tester (SJ-201,Mitutoyo Corporation, Kanagawa, Japan), as shown in Figure 2. The average values of readings are depicted in Table 4.

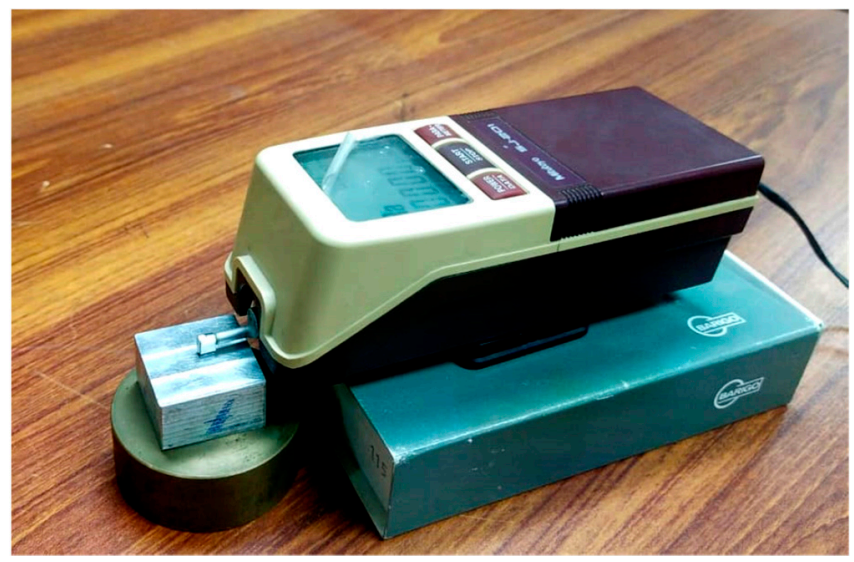

Figure 2. Surface roughness measurement.

The weight loss method was used for measuring the material removal rate (MRR) and it is expressed in Equation (1) [39]. 


$$
M R R=\frac{W_{b}-W_{a}}{\rho t_{m}}
$$

where $W_{b}$ is the weight of the sample before machining, $W_{a}$ is the weight of the sample after machining, $\rho$ is the material density, and $t_{m}$ is the machining time.

In the presented study, tool life is measured as flank wear that occurs on the relief or flank of the cutting tool [51]. The wear is measured according to the ISO 8688-2:1989 standard using a scanning electron microscope (SEM). According to this standard, the tool life is said to be diminished completely when the average flank wear exceeds $300 \mu \mathrm{m}$. Figure 3 shows a SEM image of the average flank wear for machining experiment number 1, as given in Table 4.

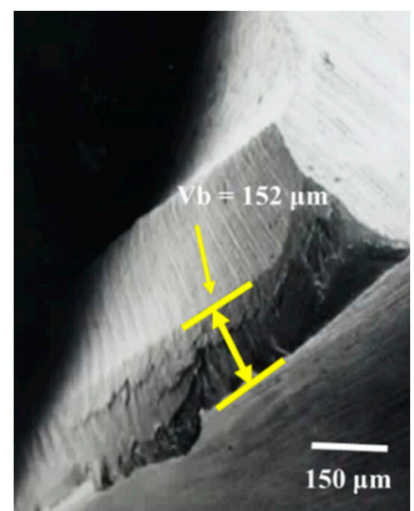

Figure 3. SEM of flank wear (experiment number 1).

\subsection{Experimentation}

Experiments were designed based on the Taguchi mixture design. The Taguchi orthogonal array (OA) mixture design (L16) with 16 experimental runs was selected and experiments were conducted on a vertical-type machining center, LG-500 HARTFORD (Hartford machining centers, Shanghai, China). The machining of each sample was performed with a new cutting tool. A 4 flute carbide flat end mill cutter was used, with a diameter and length of $16 \mathrm{~mm}$ and $75 \mathrm{~mm}$, respectively. The overhung length of $20 \mathrm{~mm}$ was maintained in order to avoid the influence of vibration and chatter. Experimental data collected through the OA are presented in Table 4.

Table 4. Design matrix in coded and experimentation results.

\begin{tabular}{|c|c|c|c|c|c|c|c|c|c|c|c|c|c|c|c|}
\hline \multirow{2}{*}{$\begin{array}{l}\text { Exp. } \\
\text { No. }\end{array}$} & \multicolumn{10}{|c|}{ Parameters } & \multicolumn{5}{|c|}{ Responses } \\
\hline & $S$ & $\mathbf{F}$ & D & W & $\mathrm{C}$ & $S$ & F & D & $\mathbf{W}$ & $\mathrm{C}$ & $\begin{array}{c}\mathrm{Ra} \\
(\mu \mathrm{m})\end{array}$ & $\begin{array}{c}\mathrm{Rq} \\
(\mu \mathrm{m})\end{array}$ & $\begin{array}{c}\mathrm{Rz} \\
(\mu \mathrm{m})\end{array}$ & $\begin{array}{c}\text { MRR } \\
\left(\mathrm{mm}^{3} / \mathrm{s}\right)\end{array}$ & $\begin{array}{c}\mathrm{V}_{\mathrm{b}} \\
(\mathrm{mm})\end{array}$ \\
\hline 1 & 1 & 1 & 1 & 1 & 1 & 1000 & 250 & 1 & 2 & Dry & 1.55 & 3.16 & 4.51 & 450 & 152 \\
\hline 2 & 1 & 2 & 2 & 2 & 1 & 1000 & 350 & 1.5 & 6 & Dry & 1.72 & 3.45 & 4.92 & 970 & 196 \\
\hline 3 & 1 & 3 & 3 & 3 & 2 & 1000 & 450 & 2 & 10 & MQL & 1.98 & 3.98 & 5.69 & 1420 & 222 \\
\hline 4 & 1 & 4 & 4 & 4 & 2 & 1000 & 550 & 2.5 & 14 & MQL & 2.35 & 4.38 & 6.25 & 2050 & 248 \\
\hline 5 & 2 & 1 & 2 & 3 & 2 & 2000 & 250 & 1.5 & 10 & MQL & 1.53 & 3.07 & 4.39 & 1085 & 168 \\
\hline 6 & 2 & 2 & 1 & 4 & 2 & 2000 & 350 & 1 & 14 & MQL & 1.64 & 3.28 & 4.69 & 1250 & 175 \\
\hline 7 & 2 & 3 & 4 & 1 & 1 & 2000 & 450 & 2.5 & 2 & Dry & 1.92 & 3.88 & 5.52 & 1415 & 243 \\
\hline 8 & 2 & 4 & 3 & 2 & 1 & 2000 & 550 & 2 & 6 & Dry & 2.13 & 4.26 & 6.09 & 1650 & 262 \\
\hline 9 & 3 & 1 & 3 & 4 & 1 & 3000 & 250 & 2 & 14 & Dry & 1.6 & 3.22 & 4.61 & 1290 & 215 \\
\hline 10 & 3 & 2 & 4 & 3 & 1 & 3000 & 350 & 2.5 & 10 & Dry & 1.89 & 3.78 & 5.41 & 1850 & 269 \\
\hline 11 & 3 & 3 & 1 & 2 & 2 & 3000 & 450 & 1 & 6 & MQL & 1.82 & 3.62 & 5.18 & 1515 & 242 \\
\hline 12 & 3 & 4 & 2 & 1 & 2 & 3000 & 550 & 1.5 & 2 & MQL & 1.86 & 3.68 & 5.27 & 1802 & 261 \\
\hline 13 & 4 & 1 & 4 & 2 & 2 & 4000 & 250 & 2.5 & 6 & MQL & 1.45 & 2.62 & 3.75 & 1482 & 232 \\
\hline 14 & 4 & 2 & 3 & 1 & 2 & 4000 & 350 & 2 & 2 & MQL & 1.61 & 3.12 & 4.48 & 1655 & 258 \\
\hline 15 & 4 & 3 & 2 & 4 & 1 & 4000 & 450 & 1.5 & 14 & Dry & 1.92 & 3.88 & 5.55 & 2100 & 295 \\
\hline
\end{tabular}




\subsection{Optimization Methodology}

Taguchi signal-to-noise (SN) ratio, which is a mono-objective optimization process, is widely applied for identifying the optimal parameter settings of individual responses but is not used simultaneously [52,53].

The expression for the larger-the-better (LTB) $\mathrm{S} / \mathrm{N}$ ratio is shown in Equation (2):

$$
S / N \text { ratio }_{L T B}=\eta=(-10) \times \log _{10}\left(\frac{1}{m}\right) \sum_{i=1}^{m} \frac{1}{z_{i j}^{2}} .
$$

The expression for the smaller-the-better (STB) S/N ratio is shown in Equation (3):

$$
S / N \text { ratio }_{\text {STB }}=\eta=(-10) \times \log _{10}\left(\frac{1}{m}\right) \sum_{i=1}^{m} z_{i j}^{2},
$$

where $m$ is the number of replications and $z_{i j}$ is the collected experimental data.

Machining processes involve multiple responses, and machining quality heavily depends on the simultaneous optimization of all quality responses [39]. Therefore, in most practical scenarios researchers demand the simultaneous optimization of all quality responses [54]. Thus, an attempt was made to complete the simultaneous optimization of quality responses using PCA coupled with CDF. The multi-optimization concept is shown in Figure 4.

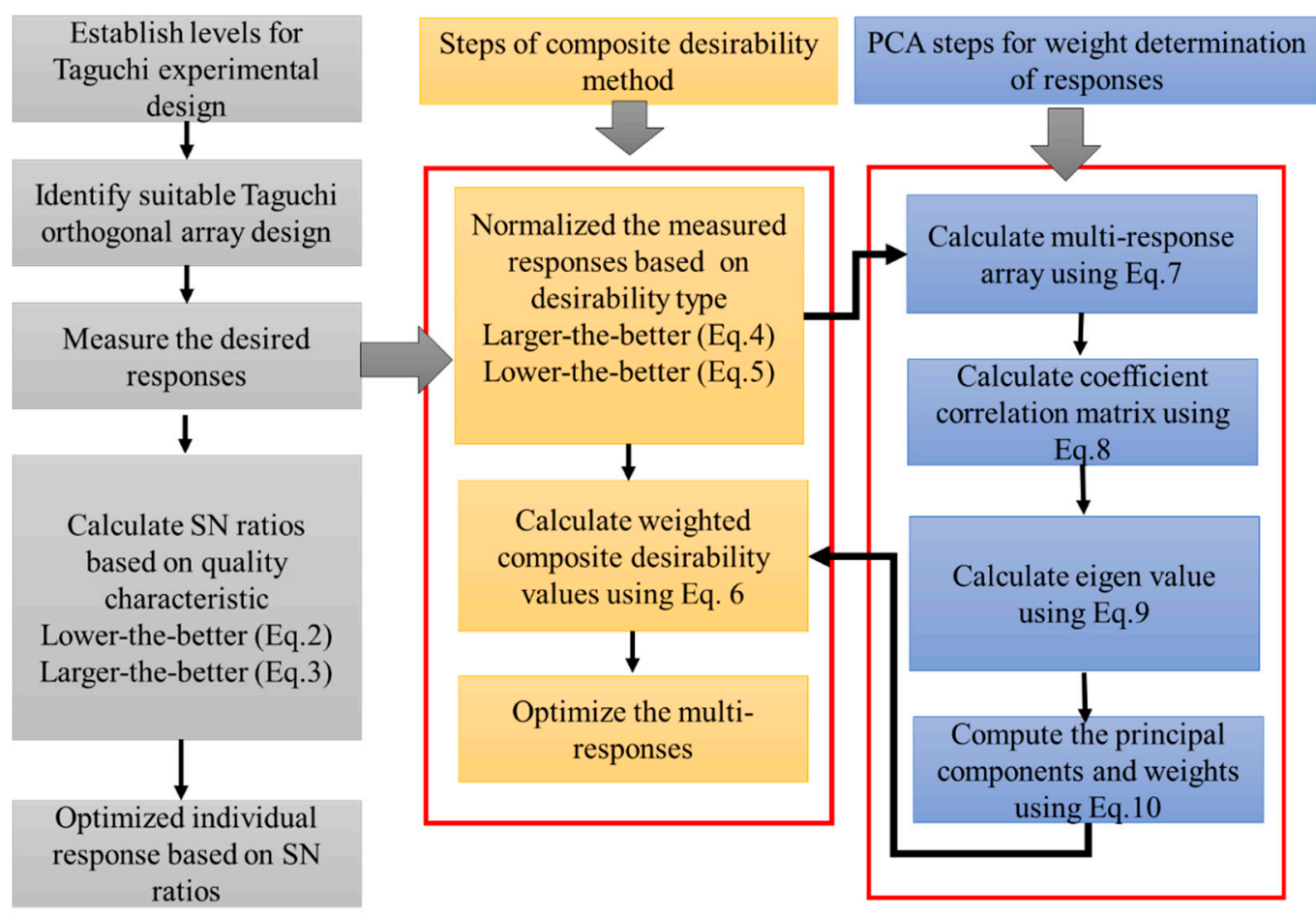

Figure 4. Conceptual framework for multi-objective optimization.

The composite desirability function is a sophisticated multi-optimization technique that can be used for real-life problems and preserves the clashing of responses under harsh conditions [55]. The procedure begins with the calculation of the desirability function value. Depending upon the goal type of response optimization, the following are the three categories (STB and LTB, as expressed in Equations (4) and (5), respectively) [39]:

$$
d_{i r(\min )}=\left[\begin{array}{c}
0, \quad y_{i r} \leq \min y_{i r} \\
{\left[\frac{y_{i r}-\max y_{i r}}{\min y_{i r}-\max y_{i r}}\right]^{a} \min y_{i r} \leq y_{i} \leq \max y_{i r}} \\
1, \quad y_{i r} \geq \max y_{i r}
\end{array}\right],
$$




$$
d_{i r(\max )}=\left[\begin{array}{c}
0, \quad y_{i r} \leq \min y_{i r} \\
{\left[\frac{y_{i r}-\min y_{i r}}{\min y_{i r}-\max y_{i r}}\right]^{a} \min y_{i r} \leq y_{i} \leq \max y_{i r}} \\
1, y_{i r} \geq \max y_{i r}
\end{array}\right]
$$

where $d_{i}$ is the desirability value of the quality response for the $i$ th treatment and $k$ th quality response, $Y_{i r}$ is the observed value of the response with the $i$ th treatment, $\max y_{i r}$ and miny $_{i r}$ are the maximum and minimum values of observed data at the $k$ th response, $T$ is the required target value, and $a$ is the assigned weight that varies from 0.1 to 10 . This determines the desirability function distribution on the interval between the upper and lower target and limit.

When $a=1$, the desirability function is linear and equal weights are assigned to the target value and its lower and upper limits. When $a<1$, the desirability function will increase exponentially (concave down) and it imparts low importance to the target. When $a$ $>1$, the desirability function will increase exponentially (concave upward). In this research, " $a$ " is set at 1 , so that the desirability function is expected to increase linearly and the values will vary between $[0,1]$. If the observed value $\left(y_{i}\right)$ exceeds the stated criteria (i.e., LTB), the desirability value approaches 1 or near to 1 . However, if the observed value $\left(y_{i}\right)$ is less than the stated criteria, then the desirability value becomes 0 and is unacceptable [56]. The overall composite desirability (D) is obtained by combining the individual desirability values of all responses [57] using Equation (6).

$$
D_{i}=\prod_{r=1}^{n} d_{r}^{w_{r}},
$$

where $D_{i}$ is the combined composite desirability value for the $i$ th treatment, $d_{r}^{w_{r}}$ is the desirability value of the $r$ th response, and $w$ is the weight assigned to each response when $\sum_{r=1}^{n} w_{r}=1$. The $i$ th treatment that yields a higher $D$ value-i.e., 1 or a closer value-represents the best response, and the treatment setting is selected as an optimal combination. Whereas, when the $i$ th treatment yields $D=0$ or a closer value, it represents an unacceptable response [57]. Finally, the optimized milling parameters are calculated by averaging the composite desirability values at identified levels for each parameter.

The reliability of multi-objective optimization mainly relies on the method employed for determining the priority weights for each quality characteristic [58]. Usually, equal importance is given to the responses in simple problems. However, weights may vary for multi-criteria decision-making (MCDM), as effective decision-making requires appropriate weight assignment [59]. Unequal weights can be obtained from numerous weight determination methods, such as principal component analysis (PCA), entropy [60], and the standard deviation method [61]. PCA is a powerful method widely aimed at presenting correlated variables into uncorrelated principal components [62]. It is a multivariate statistical method for multi-optimization that aims to minimize vagueness, correlation, dimensions of information, and complexity [62]. PCA is a preferable method to entropy, GRA, and the standard deviation method, as it preserves actual unique information to the maximum possible extent. It focuses on conserving unique information by employing linear permutations [63]. Accordingly, PCA translates multi-objective optimization to monoobjective optimization without compromising the unique statistics [64]. Therefore, PCA is deployed to determine the relative weights for each response, and the weights are integrated with CDF to perform multi-objective optimization. For multi-response optimization cases, such as CDF, the respective weights of the responses are required for the computation of the multi-performance index (MPI), called $D_{i}$, which are computed by conducting PCA on desirability values $d_{i r}$ for each quality response [65]. The PCA method begins with the data normalization of $d_{i r}$ followed by the computation of the correlation coefficient matrix (M), eigenvalues, and eigenvectors, and finishes with principal components (PCs) [62]. 
Step 01: Data Normalization: Data pre-processing: this involves the normalization of observed quality responses between 0 and 1 . The data are linearly normalized in between zero and unity depending upon the criteria employed to evaluate the responses. STB criteria are adopted for $\mathrm{Ra}, \mathrm{Rq}, \mathrm{Rz}$, and $\mathrm{Vb}$ and LTB criteria are employed for MRR using Equations (4) and (5), respectively.

Step 02: Development of the correlation coefficient matrix: Using computed composite desirability values $\left(d_{i r}\right)$, a multi-response array $(G)$ is formulated, which is presented in Equation (7).

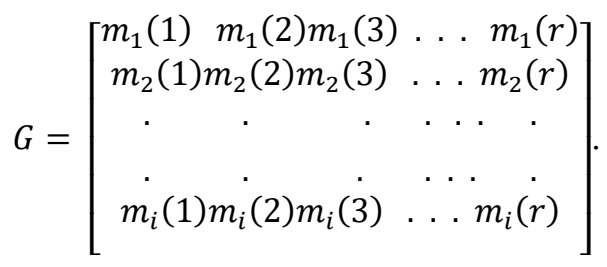

The expression for the generation of a correlation coefficient matrix $(M)$ using the multi-response array $(G)$ is shown in Equation (8).

$$
M_{r, l}=\left(\frac{\operatorname{Cov}\left(m_{a}(b), m_{a}(l)\right.}{\sqrt{\operatorname{Var}\left(m_{a}(r)\right)} \times \sqrt{\operatorname{Var}\left(m_{a}(l)\right)}}\right),
$$

where $a=1,2, \ldots, i, b=1,2, \ldots, r, l=1,2, \ldots, r$, and $\operatorname{Cov}\left(m_{a}(b), m_{a}(l)\right)$ is the covariance of sequences $m_{a}(b)$ and $m_{a}(l)$.

Step 04: Eigenvalue and eigenvector evaluation: The eigenvalues $\left(\lambda_{r}\right)$ and eigenvectors $\left(V_{r}\right)$ are generated using the $M_{r, l}$ matrix, as per Equation (9):

$$
\left(\mathrm{M}-\lambda_{r} I_{i}\right) \times V_{r}=0 .
$$

Step 05: Find principal components and weights: The uncorrelated principal components $\left(Z_{a r}\right)$ are developed with Equation (10):

$$
Z_{a r}=\sum_{i=1}^{n} m_{i}(a) \times V_{r} .
$$

The computed principal components ( $\mathrm{PC}^{\prime}$ s), eigenvalues, and eigenvectors are arranged with respect to their corresponding variance contribution.

Figure 5 summarizes the research methodology deployed in the present study. 


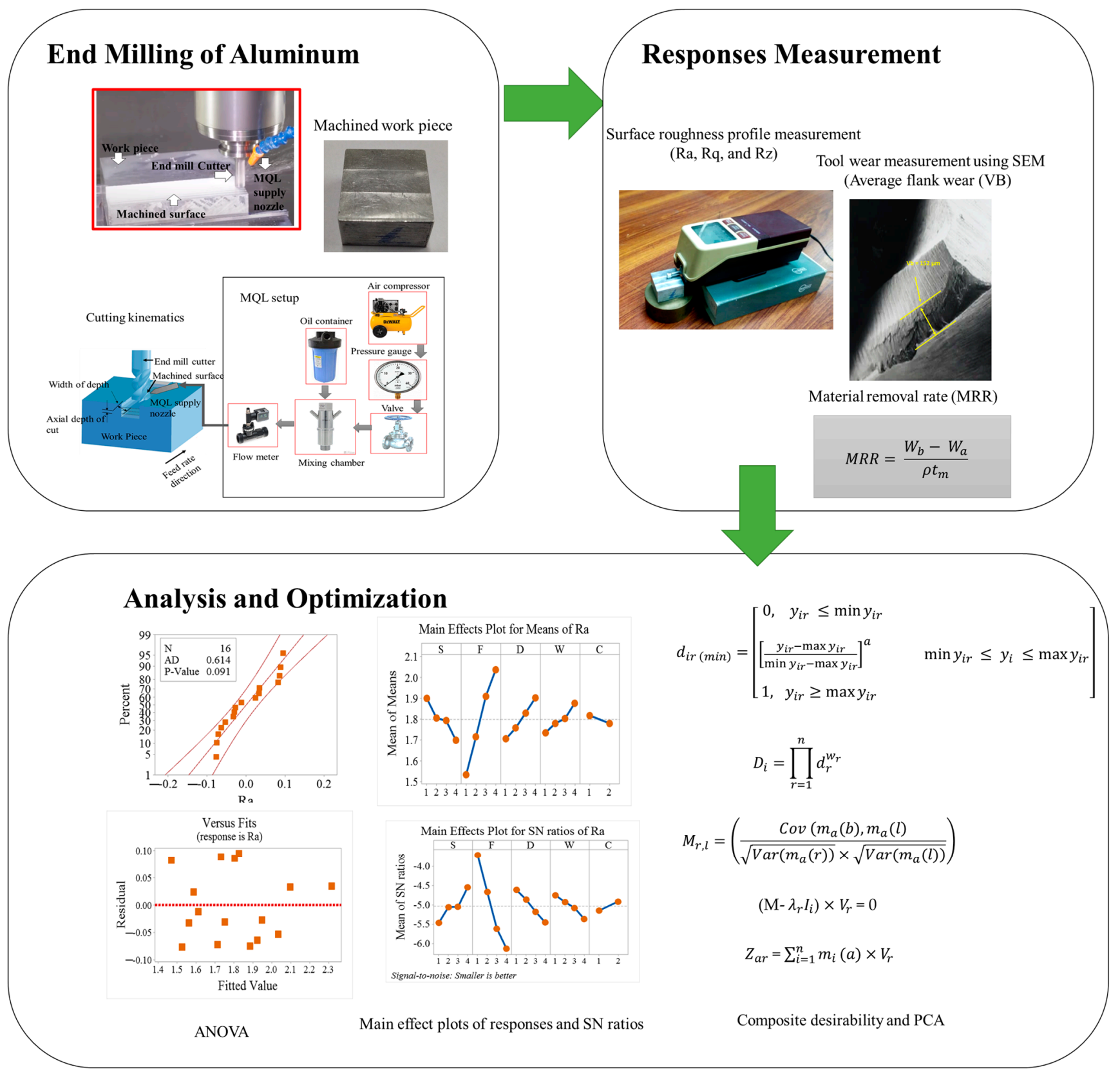

Figure 5. Research methodology.

\section{Results and Discussion}

\subsection{Analysis of Variance (ANOVA)}

Analysis of variance (ANOVA) was employed for analyzing the significance and percentage contribution of parameters regarding the response variables and suitability of experimental data for further analysis. ANOVA was conducted at a 95\% confidence interval and we obtained results for the surface roughness parameters (i.e., Ra, Rq, Rz), MRR, and $\mathrm{V}_{\mathrm{b}}$. The ANOVA results are depicted in Table 5. A $p$-value less than or equal to 0.05 shows the significance of the parameters. It is evident from Table 5 that feed rate followed by spindle speed and axial depth of cut has a significant effect on the surface roughness profile ( $\mathrm{Ra}, \mathrm{Rq}$, and $\mathrm{Rz})$, material removal rate (MRR), and tool flank wear $\left(\mathrm{V}_{\mathrm{b}}\right)$, while cutting conditions were found to be insignificant for all the considered responses. The width of cut was found to be significant only for Ra and MRR. Further, the percentage contribution of feed rate was relatively high for all the responses-i.e., $\mathrm{Ra}(68.27 \%), \mathrm{Rq}(66.32 \%), \mathrm{Rz}$ 
(66.07\%), MRR (44.68\%), and $\mathrm{V}_{\mathrm{b}}(42.98 \%)$ - thus making it one of the most significant contributing factors compared to spindle speed, axial depth of cut, width of cut, and cutting conditions. These results are in line with the published literature reports, which show the feed rate to be the most influential parameter for the surface roughness profile $[23,29,42]$, material removal rate [29], and tool wear [26,28].

Table 5. ANOVA for individual quality responses.

\begin{tabular}{|c|c|c|c|c|c|c|c|}
\hline & Source & DF & Adj SS & Adj MS & F-Value & $p$-Value & $\%$ Contribution \\
\hline \multirow{7}{*}{$\mathrm{Ra}$} & $S$ & 1 & 0.08 & 0.08 & 14.11 & 0.00 & 9.04 \\
\hline & $\mathrm{F}$ & 1 & 0.58 & 0.58 & 107.30 & 0.00 & 68.74 \\
\hline & $\mathrm{D}$ & 1 & 0.09 & 0.09 & 16.23 & 0.00 & 10.40 \\
\hline & W & 1 & 0.04 & 0.04 & 7.43 & 0.02 & 4.76 \\
\hline & $\mathrm{C}$ & 1 & 0.01 & 0.01 & 1.03 & 0.33 & 0.66 \\
\hline & Error & 10 & 0.05 & 0.01 & & & \\
\hline & Total & 15 & 0.85 & & & & \\
\hline \multirow{7}{*}{$\mathrm{Rq}$} & $S$ & 1 & 0.38 & 0.38 & 12.20 & 0.01 & 11.48 \\
\hline & $\mathrm{F}$ & 1 & 2.18 & 2.18 & 70.51 & 0.00 & 66.32 \\
\hline & $\mathrm{D}$ & 1 & 0.16 & 0.16 & 5.11 & 0.05 & 4.81 \\
\hline & W & 1 & 0.13 & 0.13 & 4.18 & 0.07 & 3.93 \\
\hline & $\mathrm{C}$ & 1 & 0.13 & 0.13 & 4.30 & 0.07 & 4.04 \\
\hline & Error & 10 & 0.31 & 0.03 & & & \\
\hline & Total & 15 & 3.29 & & & & \\
\hline \multirow{7}{*}{$\mathrm{Rz}$} & $S$ & 1 & 0.75 & 0.74 & 11.09 & 0.01 & 11.19 \\
\hline & F & 1 & 4.40 & 4.40 & 65.47 & 0.00 & 66.07 \\
\hline & $\mathrm{D}$ & 1 & 0.33 & 0.33 & 4.88 & 0.05 & 4.92 \\
\hline & W & 1 & 0.26 & 0.26 & 3.94 & 0.08 & 3.97 \\
\hline & $\mathrm{C}$ & 1 & 0.25 & 0.25 & 3.72 & 0.08 & 3.75 \\
\hline & Error & 10 & 0.67 & 0.07 & & & \\
\hline & Total & 15 & 6.66 & & & & \\
\hline \multirow{7}{*}{ MRR } & $S$ & 1 & 731,149 & 731,149 & 58.95 & 0.00 & 26.88 \\
\hline & F & 1 & $1,215,245$ & $1,215,245$ & 97.98 & 0.00 & 44.68 \\
\hline & $\mathrm{D}$ & 1 & 345,056 & 345,056 & 27.82 & 0.00 & 12.69 \\
\hline & W & 1 & 275,186 & 275,186 & 22.19 & 0.00 & 10.12 \\
\hline & $\mathrm{C}$ & 1 & 29,241 & 29,241 & 2.36 & 0.16 & 1.08 \\
\hline & Error & 10 & 124,029 & 12,403 & & & \\
\hline & Total & 15 & $2,719,906$ & & & & \\
\hline \multirow{7}{*}{$\mathrm{V}_{\mathrm{b}}$} & $S$ & 1 & 9159.20 & 9159.20 & 57.10 & 0.00 & 36.26 \\
\hline & $\mathrm{F}$ & 1 & $10,857.80$ & $10,857.80$ & 67.69 & 0.00 & 42.98 \\
\hline & $\mathrm{D}$ & 1 & 3001.30 & 3001.30 & 18.71 & 0.00 & 11.88 \\
\hline & W & 1 & 39.20 & 39.20 & 0.24 & 0.63 & 0.16 \\
\hline & $\mathrm{C}$ & 1 & 600.30 & 600.30 & 3.74 & 0.08 & 2.38 \\
\hline & Error & 10 & 1604.00 & 160.40 & & & \\
\hline & Total & 15 & $25,261.80$ & & & & \\
\hline
\end{tabular}

DF (degree sof freedom), Adj SS (adjusted sum of square), Adj MS (adjusted mean square), F-value (Fisher test value), $p$ value (probability value).

The reliability and adequacy of the ANOVA results were analyzed by analyzing residual (error) plots, as shown in Figures 6 and 7. These plots display the data visually between residual and fitted values so that the reliability of the assumptions can be checked efficiently. The assumptions need to be satisfied for adequate ANOVA-i.e., the residuals are normally distributed and have constant variance $[63,66]$. It is quite evident from the normality plot of the residuals (shown in Figure 6) that most data points lie close to the fitted line at a 95\% confidence interval (CI) for each response plot, thus confirming that the residuals are normally distributed. Further, the normality assumption was checked by 
the Anderson Darling (AD) test at a $95 \% \mathrm{CI}$. The AD test is an extremely powerful and widely used statistical tool [67]. The null hypothesis of the AD test claims that the data follow a normal distribution-i.e., $p>0.05-$ whereas the alternative hypothesis denies the claim stated in the null hypothesis-i.e., $p \leq 0.05$. The $p$-value of the responses shown in Figure 6 is greater than 0.05 , thus confirming the normal distribution of the residuals. The versus fit plots shown in Figure 7 verify the assumption of constant variance, depicting that the data are completely randomized on both sides of the fitted line and no patterns are identified (curvilinear and uneven spreading) [66]. Thus, the constant variance assumption is also satisfied. Based upon the satisfaction of the assumptions, normality plots, and versus plots, the data were fit for further analysis and optimization [39].
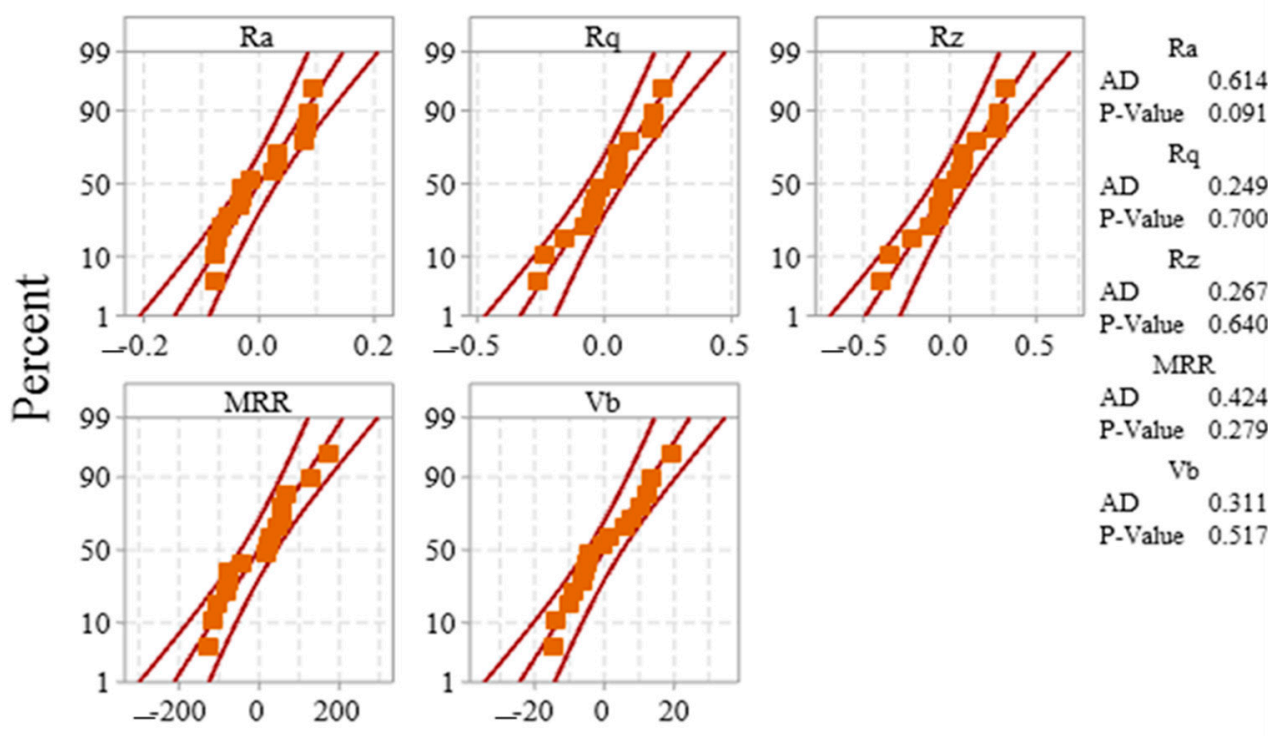

Palue 0.517

Figure 6. Normal probability plots of responses.
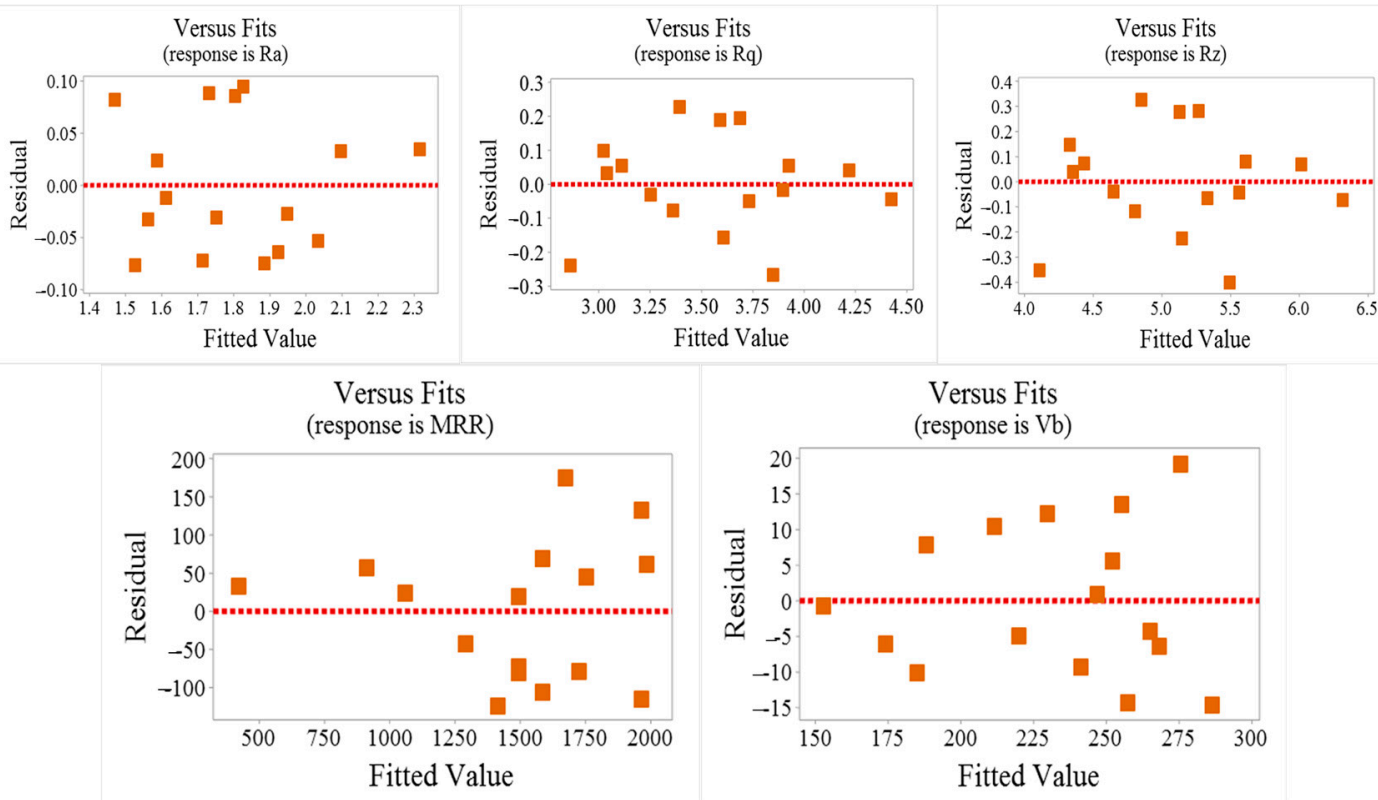

Figure 7. Versus fits plots of responses. 


\subsection{Main Effects Plots of Means for Individual Responses}

Figure 8 presents the main effects of cutting parameters on the surface roughness profile (i.e., $\mathrm{Ra}, \mathrm{Rq}, \mathrm{Rz}$ ), MRR, and $\mathrm{Vb}$. As shown in Figure $8 \mathrm{a}-\mathrm{c}$, a decreasing trend for surface roughness profile is observed with the rise in spindle speed and under MQL conditions. However, an increase in the surface roughness profile is observed with an increase in the feed rate, axial depth of cut, and width of cut. The decrease in surface roughness with an increase in cutting speed is attributed to the thermal softening of aluminum alloys, elimination of built-up edges (BUE), decrease in chip fracture, and increase in plastic behavior $[20,43]$. Compared to dry machining, MQL tends to reduce the thermal distortion of the machined work piece and also flushes away the machined chips [43]. The increase in surface roughness profile with an increase in feed rate and depth of cut (both axial and width) occurs due to vibration, an increase in cutting forces, the kinematic-geometric mapping of the cutting edge in the workpiece, and heat generation at the tool and work piece interface $[44,45]$. Figure $8 \mathrm{~d}$ shows a remarkable rise in MRR with the increase in spindle speed, feed rate, axial depth of cut, and width of cut under MQL conditions. This may be attributed to an increase in the plastic behavior of aluminum alloy and the fact that the application of MQL reduces the formation of longer chips and facilitates the movement of the chips away from the tool's surface, therefore improving the MRR [68,69]. A rigorous increase in flank wear is noticed with an increase in spindle speed, feed rate, axial depth of cut, and width of cut. This effect decreases under the MQL environment, which is depicted in Figure 8e. This is attributed to a rise in cutting temperature that generates high residual stresses in the machined surface layer, thermal distortion at the tooltip, and the sticking of work material to the tooltip, therefore accelerating the flank wear [46,47]. However, using MQL provides better control over the machining temperature and reduces the accumulation of material on the cutting surface $[47,70]$.

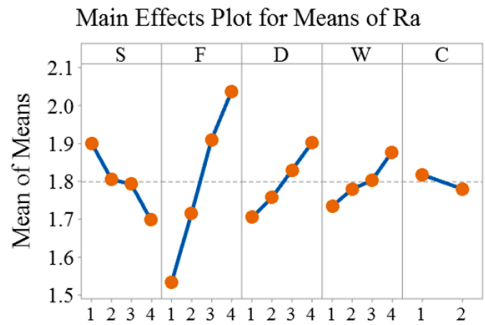

(a)

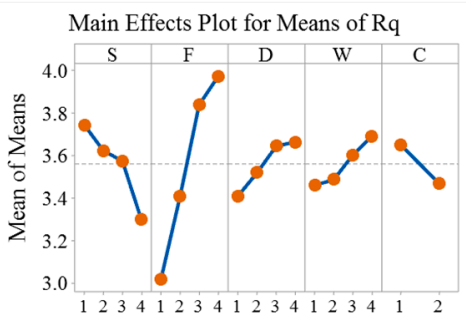

(b)

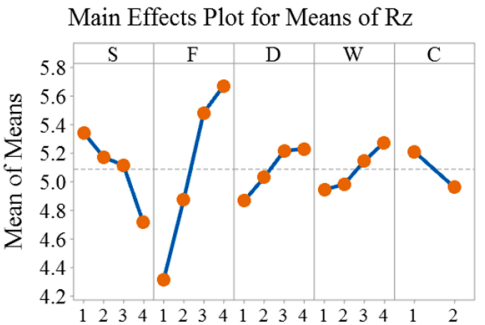

(c)

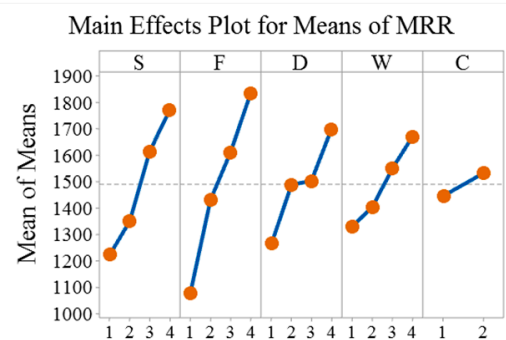

(d)

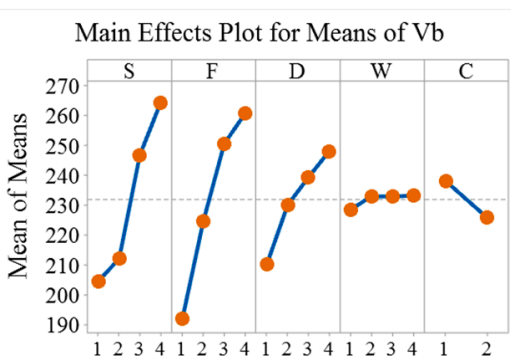

(e)

Figure 8. Main effects plots for (a) Ra, (b) Rq, (c) Rz, (d) MRR, (e) $V_{b}$.

\subsection{Single Objective Optimization}

Taguchi-based $\mathrm{S} / \mathrm{N}$ ratios were employed for the individual optimization of responses. In this research work, responses involve contradictory objective functions for single-objective optimization-i.e., the minimization of the surface roughness profile and 
flank wear and the maximization of MRR. Therefore, the-smaller-the-better criteria were used for the surface roughness profile and flank wear using Equation (3), whereas thelarger-the-better criteria were used for MRR using Equation (2).

It is quite evident from Table 6 and the main effect plots for the $\mathrm{SN}$ ratios of response variables (shown in Figure 9) that the optimal settings for parameters involve significant inconsistency among the quality responses. Therefore, the application of multi-objective optimization techniques is needed to obtain an optimal setting that satisfies all the responses simultaneously. For instance, as shown in Table 6 at experimental level 13 and Figure $9 \mathrm{a}-\mathrm{c}$, the optimized process parameters to achieve the lower surface roughness profile are cutting speed at a high level; feed rate, axial depth of cut, and width of cut at a low level; and an MQL environment. However, the optimized setting for MRR is high cutting speed, feed rate, axial depth of cut, and width of cut and MQL condition, as depicted in Table 6 at experimental run 15 and Figure 9d. Conversely, lower tool wear supports a lower cutting speed, feed rate, axial depth of cut, and width of cut under an MQL environment. This is depicted in Table 6 at experimental run 1 and Figure 9e.

Table 6. $\mathrm{S} / \mathrm{N}$ ratios of responses.

\begin{tabular}{|c|c|c|c|c|c|}
\hline \multirow{2}{*}{ Exp. No. } & \multicolumn{5}{|c|}{ S/N Ratio of Responses } \\
\hline & Ra & $\mathbf{R q}$ & $\mathbf{R z}$ & MRR & $V_{b}$ \\
\hline 1 & -3.81 & -9.99 & -13.08 & 53.06 & $-43.64 *$ \\
\hline 2 & -4.71 & -10.76 & -13.84 & 59.74 & -45.85 \\
\hline 3 & -5.93 & -12.00 & -15.10 & 63.05 & -46.93 \\
\hline 4 & -7.42 & -12.83 & -15.92 & 66.24 & -47.89 \\
\hline 5 & -3.69 & -9.74 & -12.85 & 60.71 & -44.51 \\
\hline 6 & -4.30 & -10.32 & -13.42 & 61.94 & -44.86 \\
\hline 7 & -5.67 & -11.78 & -14.84 & 63.02 & -47.71 \\
\hline 8 & -6.57 & -12.59 & -15.69 & 64.35 & -48.37 \\
\hline 9 & -4.08 & -10.16 & -13.27 & 62.21 & -46.65 \\
\hline 10 & -5.53 & -11.55 & -14.66 & 65.34 & -48.60 \\
\hline 11 & -5.20 & -11.17 & -14.29 & 63.61 & -47.68 \\
\hline 12 & -5.39 & -11.32 & -14.44 & 65.12 & -48.33 \\
\hline 13 & -3.23 * & $-8.37 *$ & $-11.48 *$ & 63.42 & -47.31 \\
\hline 14 & -4.14 & -9.88 & -13.03 & 64.38 & -48.23 \\
\hline 15 & -5.67 & -11.78 & -14.89 & $66.44 *$ & -49.40 \\
\hline 16 & -5.15 & -11.08 & -14.13 & 65.34 & -48.69 \\
\hline Optimum & $\mathrm{S}_{4} \mathrm{~F}_{1} \mathrm{D}_{4} \mathrm{~W}_{2} \mathrm{C}_{2}$ & $\mathrm{~S}_{4} \mathrm{~F}_{1} \mathrm{D}_{4} \mathrm{~W}_{2} \mathrm{C}_{2}$ & $\mathrm{~S}_{4} \mathrm{~F}_{1} \mathrm{D}_{4} \mathrm{~W}_{2} \mathrm{C}_{2}$ & $\mathrm{~S}_{4} \mathrm{~F}_{3} \mathrm{D}_{2} \mathrm{~W}_{4} \mathrm{C}_{1}$ & $\mathrm{~S}_{1} \mathrm{~F}_{1} \mathrm{D}_{1} \mathrm{~W}_{1} \mathrm{C}_{1}$ \\
\hline
\end{tabular}

* Optimized setting for mono-optimization.

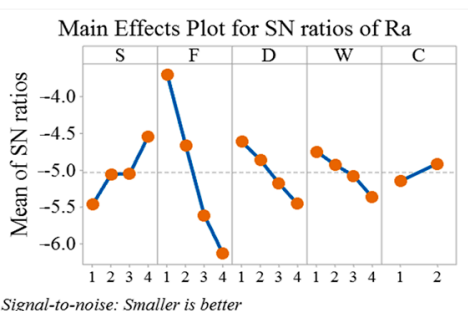

(a)

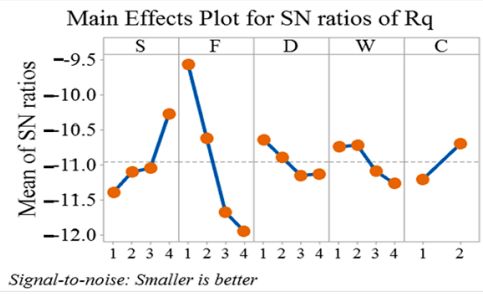

(b)

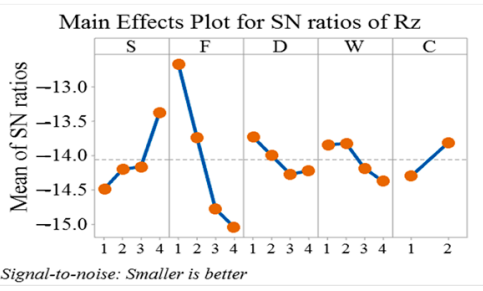

(c) 


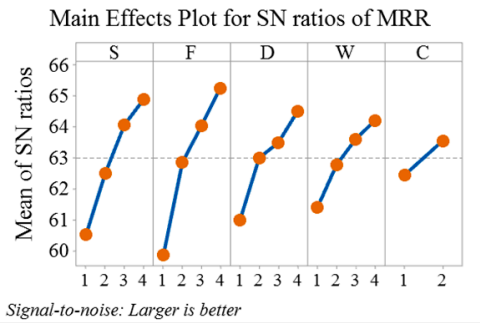

(d)

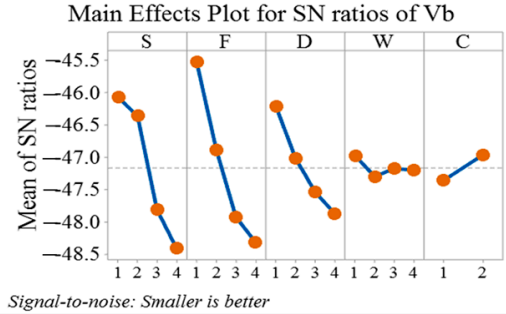

(e)

Figure 9. Main effects plots for the SN ratios of (a) Ra, (b) Rq, (c) Rz, (d) MRR, (e) $V_{b}$.

\subsection{Multi-Objective Optimization}

The multi-optimization begins with the computation of normalized values of $\mathrm{SN}$ ratios by employing the desirability function criteria as per Equations (4) and (5). The reliability of multi-objective optimization mainly relies on the method used for determining the relative importance (weights) for each quality characteristic [58]. Table 7 presents the composite desirability values.

Table 7. Calculation of the composite desirability values.

\begin{tabular}{cccccc}
\hline \multirow{2}{*}{ Exp. No. } & \multicolumn{5}{c}{ Composite Desirability Values } \\
\cline { 2 - 6 } & $\mathbf{R a}$ & $\mathbf{R q}$ & $\mathbf{R z}$ & $\mathbf{M R R}$ & $\mathbf{V}_{\mathbf{b}}$ \\
\hline 1 & 0.889 & 0.693 & 0.696 & 0.000 & 1.000 \\
2 & 0.700 & 0.528 & 0.532 & 0.315 & 0.692 \\
3 & 0.411 & 0.227 & 0.224 & 0.588 & 0.510 \\
4 & 0.000 & 0.000 & 0.000 & 0.970 & 0.329 \\
5 & 0.911 & 0.744 & 0.744 & 0.385 & 0.888 \\
6 & 0.789 & 0.625 & 0.624 & 0.485 & 0.839 \\
7 & 0.478 & 0.284 & 0.292 & 0.585 & 0.364 \\
8 & 0.244 & 0.068 & 0.064 & 0.727 & 0.231 \\
9 & 0.833 & 0.659 & 0.656 & 0.509 & 0.559 \\
10 & 0.511 & 0.341 & 0.336 & 0.848 & 0.182 \\
11 & 0.589 & 0.432 & 0.428 & 0.645 & 0.371 \\
12 & 0.544 & 0.398 & 0.392 & 0.819 & 0.238 \\
13 & 1.000 & 1.000 & 1.000 & 0.625 & 0.441 \\
14 & 0.822 & 0.716 & 0.708 & 0.730 & 0.259 \\
15 & 0.478 & 0.284 & 0.280 & 1.000 & 0.000 \\
16 & 0.600 & 0.455 & 0.464 & 0.848 & 0.161 \\
\hline
\end{tabular}

Therefore, PCA was utilized to compute the relative weights, which were integrated with the complicated multi-optimization technique applied in research-i.e., CDF for the extraction of the optimal solution [62]. The eigenvalues and eigenvectors were calculated as per Equation (9) and the PCs computed as per Equation (10), and the results are presented in Table 8. The percentage of total variation provided by PCA was used as a priority weight value [65]. Owing to this, the eigenvalue associated with the first principal component (PC) accounts for $77 \%$ of the variation in five quality responses; therefore, the eigenvector for the first PC was used in the computation of the relative weights for the quality response [62]. 
Table 8. Principal component analysis.

\begin{tabular}{cccccc}
\hline Component & PC 1 & PC 2 & PC 3 & PC 4 & PC 5 \\
\hline Eigenvalue & 3.852 & 1.027 & 0.0993 & 0.0216 & 0.0001 \\
Variation (\%) & 0.77 & 0.205 & 0.02 & 0.004 & 0 \\
Cumulative (\%) & 0.77 & 0.976 & 0.996 & 1 & 1 \\
\hline & 0.484 & -0.271 & -0.281 & 0.783 & -0.013 \\
Eigenvector & 0.475 & -0.351 & 0.155 & -0.347 & 0.712 \\
& 0.476 & -0.346 & 0.149 & -0.372 & -0.702 \\
& -0.404 & -0.564 & 0.659 & 0.291 & -0.01 \\
& 0.388 & 0.605 & 0.664 & 0.207 & -0.004 \\
\hline
\end{tabular}

The eigenvectors of the first PCs were squared for the computation of the relative weights of each performance index [56]. The weights $0.2343,0.2256,0.2266,0.1632$, and 0.1505 were assigned to $\mathrm{Ra}, \mathrm{Rq}, \mathrm{Rz}, \mathrm{MRR}$, and $\mathrm{V}_{\mathrm{b}}$, respectively, as shown in Table 9.

Table 9. Variance contribution of quality responses for PC 1.

\begin{tabular}{cc}
\hline Response Variable & Contribution \\
\hline $\mathrm{Ra}$ & 0.2343 \\
$\mathrm{Rq}$ & 0.2256 \\
$\mathrm{Rz}$ & 0.2266 \\
$\mathrm{MRR}$ & 0.1632 \\
$\mathrm{Vb}$ & 0.1505 \\
\hline
\end{tabular}

The weighted composite desirability values for quality characteristics were computed by assigning respective priority weights as exponents to the composite desirability values (as per Figure 4). Using Equation (6), the product of the weighted composite resulted in overall desirability. This is illustrated in Table 10. The optimal settings were obtained by averaging the $D_{i}$ values at the respective levels of each parameter, as illustrated in Table 11.

Table 10. Weighted and overall composite desirability.

\begin{tabular}{|c|c|c|c|c|c|c|c|}
\hline \multirow{2}{*}{ Exp. No. } & \multicolumn{5}{|c|}{ Weighted Composite Desirability Values } & \multirow{2}{*}{ Overall Desirability $\left(D_{i}\right)$} & \multirow{2}{*}{ Rank } \\
\hline & $\mathbf{R a}$ & $\mathbf{R q}$ & $\mathbf{R z}$ & MRR & $\mathbf{V}_{\mathbf{b}}$ & & \\
\hline 1 & 0.97 & 0.92 & 0.92 & 0.00 & 1.00 & 0.0000 & 14 \\
\hline 2 & 0.92 & 0.87 & 0.87 & 0.83 & 0.95 & 0.5402 & 6 \\
\hline 3 & 0.81 & 0.72 & 0.71 & 0.92 & 0.90 & 0.3443 & 12 \\
\hline 4 & 0.00 & 0.00 & 0.00 & 0.99 & 0.85 & 0.0000 & 14 \\
\hline 5 & 0.98 & 0.94 & 0.94 & 0.86 & 0.98 & 0.7196 & 2 \\
\hline 6 & 0.95 & 0.90 & 0.90 & 0.89 & 0.97 & 0.6619 & 3 \\
\hline 7 & 0.84 & 0.75 & 0.76 & 0.92 & 0.86 & 0.3746 & 11 \\
\hline 8 & 0.72 & 0.55 & 0.54 & 0.95 & 0.80 & 0.1625 & 13 \\
\hline 9 & 0.96 & 0.91 & 0.91 & 0.90 & 0.92 & 0.6513 & 4 \\
\hline 10 & 0.85 & 0.78 & 0.78 & 0.97 & 0.77 & 0.3956 & 10 \\
\hline 11 & 0.88 & 0.83 & 0.83 & 0.93 & 0.86 & 0.4845 & 7 \\
\hline 12 & 0.87 & 0.81 & 0.81 & 0.97 & 0.81 & 0.4457 & 9 \\
\hline 13 & 1.00 & 1.00 & 1.00 & 0.93 & 0.88 & 0.8187 & 1 \\
\hline 14 & 0.96 & 0.93 & 0.92 & 0.95 & 0.82 & 0.6365 & 5 \\
\hline 15 & 0.84 & 0.75 & 0.75 & 1.00 & 0.00 & 0.0000 & 14 \\
\hline 16 & 0.89 & 0.84 & 0.84 & 0.97 & 0.76 & 0.4593 & 8 \\
\hline
\end{tabular}


Table 11. Response table for multi-optimization.

\begin{tabular}{cccccccc}
\hline \multirow{2}{*}{ Cutting Parameters } & \multicolumn{4}{c}{ Mean of $\boldsymbol{D}_{\boldsymbol{i}}$} & Delta & Rank \\
\cline { 2 - 5 } & $\mathbf{1}$ & $\mathbf{2}$ & $\mathbf{3}$ & $\mathbf{4}$ & & 2 \\
Cutting speed & 0.221 & 0.480 & $0.494^{*}$ & 0.478 & 0.2731 & 1 \\
Feed rate & 0.547 & $0.558^{*}$ & 0.301 & 0.269 & 0.2917 & 5 \\
Depth of cut & 0.401 & 0.426 & $0.448^{*}$ & 0.397 & 0.0514 & 4 \\
Width of Cut & 0.364 & $0.501^{*}$ & 0.479 & 0.328 & 0.1732 & 3 \\
Cutting conditions & 0.329 & $0.513^{*}$ & - & - & 0.1910 & 3 \\
\hline
\end{tabular}

* Optimal levels of multi-optimization.

\section{Confirmatory Experiment}

The reproducibility of the results, model adequacy, and validation of the optimal combination of machining parameters identified in Table 12 were verified by conducting three confirmatory experiments. The results of the confirmatory experiments show quite significant and pronounced improvements compared to the initial conditions, as shown in Table 12.

Table 12. Comparative summary of confirmatory experiments.

\begin{tabular}{cccc}
\hline Responses & $\begin{array}{c}\text { Initial Condition } \\
\mathbf{S}_{2} \mathbf{F}_{3} \mathbf{D}_{4} \mathbf{W}_{\mathbf{1}} \mathbf{C}_{\mathbf{1}}\end{array}$ & PCA-CDF & $\begin{array}{c}\text { \% Improvement } \\
\text { from Initial Condition }\end{array}$ \\
\hline $\mathrm{Ra}$ & 1.92 & 1.51 & 21 \\
$\mathrm{Rq}$ & 3.88 & 3.02 & 23 \\
$\mathrm{Rz}$ & 5.52 & 4.52 & 18 \\
$\mathrm{MRR}$ & 1415 & 1851 & 30 \\
$\mathrm{Vb}$ & 243 & 198 & 22 \\
Optimal Condition & - & $\mathrm{S}_{3} \mathrm{~F}_{2} \mathrm{D}_{3} \mathrm{~W}_{2} \mathrm{C}_{2}$ & - \\
$D_{i}$ & 0.375 & 0.460 & 22 \\
\hline
\end{tabular}

\section{Conclusions}

This paper represents an informative contribution to our understanding of machining parameters. Lubrication methods were investigated and optimized for the milling of AA5005-H34 by applying a Taguchi orthogonal array (OA) mixture design (L16), SN ratios, ANOVA, PCA, and CDF. The obtained results are in good agreement with the published literature reports. For example, for surface roughness profile results closely conforms with that of Raju et al. [23] and Tosun et al. [29]. For the material removal rate, the results closely match those of Tosun et al. [29] and Costa et al. [42]. For tool wear, the obtained results are in line with those of Tsao et al. [26] and Rajeswari et al. [28]. The results of the statistical analysis performed on experimental values are summarized as follows:

- The PCA-CDF method found $\mathrm{S}_{3} \mathrm{~F}_{2} \mathrm{D}_{3} \mathrm{~W}_{2} \mathrm{C}_{2}$ to be the optimal setting for the milling machining of aluminum $5005 \mathrm{H} 34$.

- In terms of \% contribution, the ANOVA revealed that the feed rate is the most influential machining parameter for the SR profile. For example, the \% contributions of $\mathrm{Ra}, \mathrm{Rq}$, and $\mathrm{Rz}$ for feed rate are $68.74,66.32$, and 66.07, respectively.

- The Taguchi $\mathrm{S} / \mathrm{N}$ ratio identified that the optimal cutting parameter for the minimization of $\mathrm{SR}\left(\mathrm{Ra}, \mathrm{Rq}, \mathrm{Rz}\right.$ ) was $\mathrm{S}_{4} \mathrm{~F}_{1} \mathrm{D}_{4} \mathrm{~W}_{2} \mathrm{C}_{2} \mathrm{~T}_{1}$-i.e., a spindle speed of $4000 \mathrm{rev} / \mathrm{min}$, a feed rate of $250 \mathrm{~mm} / \mathrm{min}$, a depth of cut of $2.5 \mathrm{~mm}$, a width of cut of $6 \mathrm{~mm}$, and cutting conditions using MQL. The maximum MRR was achieved at $\mathrm{S}_{4} \mathrm{~F}_{3} \mathrm{D}_{2} \mathrm{~W}_{4} \mathrm{C}_{1}-$ i.e., spindle speed of $4000 \mathrm{rev} / \mathrm{min}$, feed rate of $450 \mathrm{~mm} / \mathrm{min}$, depth of cut of $1.5 \mathrm{~mm}$, width of cut of $14 \mathrm{~mm}$, and dry cutting conditions. For the minimization of $\mathrm{V}_{\mathrm{b}}$, the optimal levels identified were $\mathrm{S}_{1} \mathrm{~F}_{1} \mathrm{D}_{1} \mathrm{~W}_{1} \mathrm{C}_{1}$-i.e., spindle speed of $1000 \mathrm{rev} / \mathrm{min}$, feed rate of $250 \mathrm{~mm} / \mathrm{min}$, depth of cut of $1 \mathrm{~mm}$, width of cut of $2 \mathrm{~mm}$, and dry cutting conditions. 
The maximum MRR obtained under dry and MQL conditions was $2100 \mathrm{~mm}^{3} / \mathrm{s}$ and $2050 \mathrm{~mm}^{3} / \mathrm{s}$, respectively.

- The contribution of the response variables in the principal component analysis in descending order was $\mathrm{Ra}$ at $23.43 \%$, Rz at $22.66 \%$, Rq at $22.56 \%$, MRR at $16.32 \%$, and $\mathrm{Vb}$ at $15.05 \%$, respectively.

- The optimal machining parameters identified by the integrated approach of the PCACDF were spindle speed of $3000 \mathrm{rev} / \mathrm{min}$, feed rate of $350 \mathrm{~mm} / \mathrm{min}$, depth of cut of 2 $\mathrm{mm}$, width of cut of $6 \mathrm{~mm}$, and MQL conditions.

- Finally, confirmatory experiments based on PCA-CDF list a significant diminishing of $21 \%$ in $\mathrm{Ra}, 23 \%$ in $\mathrm{Rq}, 18 \%$ in $\mathrm{Rz}$, and $22 \%$ in $\mathrm{Vb}$ and an improvement of $30 \%$ in MRR. Therefore, the applied technique proved to be quite effective for multi-optimization.

- The application of MQL proved to be more efficient in comparison with dry machining due to its higher productivity, improved surface texture, and extended tool life.

- The experimental statistically optimized research findings can be offered as guidelines for the manufacturing sector. Additionally, these optimal machining conditions can be used as a baseline for improving the machinability of AA5005-H34.

- For future research work, the scope of the investigation could be enhanced by incorporating additional machining parameters to study their effect on quality responses. For example, the influence of the cutting reaction force, machining-induced stress, and nano-cutting fluids could be investigated.

Author Contributions: Conceptualization, M.I.Q.; experimentation and formal analysis, M.A.; methodology and statistical analysis, R.K.; supervision and improving the manuscript, W.S. and C.I.P.; data analysis, M.O. All authors have read and agreed to the published version of the manuscript.

Funding: The research work received no external funding.

Institutional Review Board Statement: Not applicable.

Informed Consent Statement: Not applicable.

Data Availability Statement: Data can be made available upon request.

Conflicts of Interest: The authors declare no conflict of interest.

\section{Nomenclature}

$\begin{array}{ll}M Q L & \text { minimum quantity lubricant } \\ S E M & \text { scanning electron microscope } \\ P C A & \text { principal component analysis } \\ R a & \text { average roughness } \\ R q & \text { root mean square } \\ R z & \text { depth of peaks on the surface } \\ M R R & \text { material removal rate } \\ S R & \text { surface roughness } \\ R S M & \text { response surface methodology } \\ P C A & \text { principal component analysis } \\ C D F & \text { composite desirability function } \\ V_{b} & \text { flank wear } \\ S & \text { spindle speed } \\ F & \text { feed rate } \\ D & \text { depth of cut } \\ W & \text { width of cut } \\ C & \text { cutting condition } \\ W_{b} & \text { weight of the sample before machining } \\ W_{a} & \text { weight of the sample after machining } \\ \rho & \text { material density }\end{array}$




$\begin{array}{ll}t_{m} & \text { machining time } \\ S N & \text { Taguchi signal-to-noise ( } \\ \text { LTB } & \text { larger-the-better (LTB) S/N ratio } \\ \text { STB } & \text { smaller-the-better (STB) S/N ratio } \\ \mathrm{M} & \text { number of replications } \\ z_{i j} & \text { experimental data. } \\ d_{i} & \text { desirability value of quality response } \\ Y_{i r} & \text { observed value of the response } \\ y_{i r} & \text { observed data at the kth response } \\ \mathrm{T} & \text { target value } \\ a & \text { assigned weight (varies 0.1-10) } \\ D_{i} & \text { combined composite desirability } \\ d_{r}^{w_{r}} & \text { desirability value of the rth response } \\ w & \text { assigned weight to each response } \\ M C D M & \text { multi-criteria decision making } \\ M P I & \text { multi-performance index (MPI) } \\ \mathrm{M} & \text { coefficient matrix } \\ \mathrm{G} & \text { multi-response array } \\ \lambda_{r} & \text { eigenvalues } \\ V_{r} & \text { eigenvectors } \\ B U E & \text { built-up edges (BUE) } \\ \text { PC } & \text { principal component } \\ & \end{array}$

\section{References}

1. Lian, Y.; Chen, H.; Mu, C.; Deng, J.; Lei, S. Experimental investigation and mechanism analysis of tungsten disulfide soft coated micro-nano textured self-lubricating dry cutting tools. Int. J. Precis. Eng. Manuf. Technol. 2018, 5, 219-230, doi:10.1007/s40684018-0022-9.

2. Mia, M.; Gupta, M.; Singh, G.; Krolczyk, G.; Pimenov, D.Y. An approach to cleaner production for machining hardened steel using different cooling-lubrication conditions. J. Clean. Prod. 2018, 187, 1069-1081, doi:10.1016/j.jclepro.2018.03.279.

3. Yusof, N.M.; Venkatesh, V.C.; Sharif, S. Dry turning of tempered martensitic stainless tool steel using coated cermet and coated carbide tools. J. Mater. Process. Technol. 2007, 185, 83-90, doi:10.1016/j.jmatprotec.2006.03.137.

4. Klocke, F.; Eisenblätter, G. Dry cutting. CIRP Ann. 1997, 46, 519-526, doi:10.1016/s0007-8506(07)60877-4.

5. Davoudinejad, A.; Tosello, G.; Annoni, M. Influence of the worn tool affected by built-up edge (BUE) on micro end-milling process performance: A 3D finite element modeling investigation. Int. J. Precis. Eng. Manuf. 2017, 18, 1321-1332, doi:10.1007/s12541-017-0157-6.

6. Krolczyk, G.; Maruda, R.W.; Krolczyk, J.; Wojciechowski, S.; Mia, M.; Nieslony, P.; Budzik, G. Ecological trends in machining as a key factor in sustainable production-A review. J. Clean. Prod. 2019, 218, 601-615, doi:10.1016/j.jclepro.2019.02.017.

7. De Lacalle, L.L.; Angulo, C.; Lamikiz, A.; Sánchez, J. Experimental and numerical investigation of the effect of spray cutting fluids in high speed milling. J. Mater. Process. Technol. 2006, 172, 11-15, doi:10.1016/j.jmatprotec.2005.08.014.

8. Mia, M.; Gupta, M.K.; Lozano, J.A.; Carou, D.; Pimenov, D.Y.; Królczyk, G.; Dhar, N.R. Multi-objective optimi-zation and life cycle assessment of eco-friendly cryogenic N2 assisted turning of Ti-6Al-4V. J. Clean. Prod. 2019, 210, 121-133.

9. Katna, R.; Suhaib, M.; Agrawal, N. Nonedible vegetable oil-based cutting fluids for machining pro-cesses-a review. Mater. Manuf. Process. 2020, 35, 1-32.

10. Ahsan Ul Haq, M.; Khan, A.M.; Gong, L.; Xu, T.; Meng, L.; Hussain, S. A comparative study of face mill-ing of D2 steel using $\mathrm{Al} 2 \mathrm{O} 3$ based nanofluid minimum quantity lubrication and minimum quantity lubri-cation. Adv. Sci. Technol. Res. J. 2018, 12, 99-105.

11. Gupta, M.K.; Mia, M.; Jamil, M.; Singh, R.; Singla, A.K.; Song, Q.; Liu, Z.; Khan, A.M.; Rahman, M.A.; Sarıkaya, M.; et al. Machinability investigations of hardened steel with biodegradable oil-based MQL spray system. Int. J. Adv. Manuf. Technol. 2020, 108, 735-748, doi:10.1007/s00170-020-05477-6.

12. Khan, A.M.; Gupta, M.K.; Hegab, H.; Jamil, M.; Mia, M.; He, N.; Song, Q.; Liu, Z.; Pruncu, C.I. Energy-based cost integrated model-ling and sustainability assessment of Al-GnP hybrid nanofluid assisted turning of AISI52100 steel. J. Clean. Prod. 2020, $257,120502$.

13. Khan, A.M.; Jamil, M.; Salonitis, K.; Sarfraz, S.; Zhao, W.; He, N.; Zhao, G. Multi-objective optimization of en-ergy consumption and surface quality in nanofluid SQCL assisted face milling. Energies 2019, 12, 710.

14. Li, B.; Li, C.; Zhang, Y.; Wang, Y.; Jia, D.; Yang, M. Grinding temperature and energy ratio coefficient in MQL grinding of hightemperature nickel-base alloy by using different vegetable oils as base oil. Chin. J. Aeronaut. 2016, 29, 1084-1095, doi:10.1016/j.cja.2015.10.012. 
15. Tao, F.; Cheng, J.; Qi, Q.; Zhang, M.; Zhang, H.; Sui, F. Digital twin-driven product design, manufac-turing and service with big data. Int. J. Adv. Manuf. Technol. 2018, 29, 3563-3576.

16. Nie, Z.; Lynn, R.; Tucker, T.M.; Kurfess, T. Voxel-based analysis and modeling of MRR computational accuracy in milling process. CIRP J. Manuf. Sci. Technol. 2019, 27, 78-92, doi:10.1016/j.cirpj.2019.07.003.

17. Gürbüz, H.; Emre Gönülaçar, Y. Optimization and evaluation of dry and minimum quantity lubri-cating methods on machinability of AISI 4140 using Taguchi design and ANOVA. Proc. Inst. Mech. Eng. Part C J. Mech. Eng. Sci. 2020, Volume (0), doi:10.1177/0954406220939609.

18. Abhang, L.B.; Hameedullah, M. Multi performance optimization in machining of En-31 steel alloy us-ing Taguchi-utility concept. J. Manuf. Technol. Res. 2011, 3, 265.

19. Said, Z.; Gupta, M.; Hegab, H.; Arora, N.; Khan, A.M.; Jamil, M.; Bellos, E. A comprehensive review on mini-mum quantity lubrication (MQL) in machining processes using nano-cutting fluids. Int. J. Adv. Manuf. Technol. 2019, 105, $2057-2086$.

20. Santos, M.C., Jr.; Machado, A.R.; Sales, W.F.; Barrozo, M.A.; Ezugwu, E.O. Machining of aluminum alloys: A review. Int. J. Adv. Manuf. Technol. 2016, 86, 3067-3080, doi:10.1007/s00170-016-8431-9.

21. Debnath, S.; Reddy, M.M.; Yi, Q.S. Environmental friendly cutting fluids and cooling techniques in machining: A review. J. Clean. Prod. 2014, 83, 33-47, doi:10.1016/j.jclepro.2014.07.071.

22. Jebaraj, M.; Pradeep Kumar, M.; Yuvaraj, N.; Mujibar Rahman, G. Experimental study of the influ-ence of the process parameters in the milling of Al6082-T6 alloy. Mater. Manuf. Process. 2019, 34, 1411-1427.

23. Raju, K.V.M.K.; Janardhana, G.R.; Kumar, P.N.; Rao, V.D.P. Optimization of cutting conditions for surface roughness in CNC end milling. Int. J. Precis. Eng. Manuf. 2011, 12, 383-391, doi:10.1007/s12541-011-0050-7.

24. Elsen, S.R.; Dhamodaran, K.; Aseer, J.R. Multi-Objective Optimization of End Milling Process Param-Eter for Stir Casted Alumina Reinforced Aluminium Metal Matrix Composite Using RSM. In Proceedings of the 2nd International Conference on Advances in Mechanical Engineering (ICAME 2018), Kattankulathur, India, 22-24 March, 2018.

25. Kumar, R.S.; Alexis, J.; Thangarasu, V. Optimization of high speed cnc end milling process of bsl 168 aluminium composite for aeronautical applications. Trans. Can. Soc. Mech. Eng. 2017, 41, 609-625, doi:10.1139/tcsme-2017-1043.

26. Tsao, C.C. Grey-Taguchi method to optimize the milling parameters of aluminum alloy. Int. J. Adv. Manuf. Technol. 2009, 40, 41-48, doi:10.1007/s00170-007-1314-3.

27. Lmalghan, R.; Rao, K.; ArunKumar, S.; Rao, S.S.; Herbert, M.A. Machining parameters optimization of aa6061 using response surface methodology and particle swarm optimization. Int. J. Precis. Eng. Manuf. 2018, 19, 695-704, doi:10.1007/s12541-018-00832 .

28. Rajeswari, B.; Amirthagadeswaran, K. Experimental investigation of machinability characteristics and multi-response optimization of end milling in aluminium composites using RSM based grey relational analysis. Measurement 2017, 105, 78-86, doi:10.1016/j.measurement.2017.04.014.

29. Tosun, N.; Pihtili, H. Gray relational analysis of performance characteristics in MQL milling of 7075 Al alloy. Int. J. Adv. Manuf. Technol. 2010, 46, 509-515, doi:10.1007/s00170-009-2118-4.

30. Abas, M.; Salah, B.; Khalid, Q.S.; Hussain, I.; Babar, A.R.; Nawaz, R.; Khan, R.; Saleem, W. Experimental investigation and statistical evaluation of optimized cutting process parameters and cutting conditions to minimize cutting forces and shape deviations in Al6026-T9. Materials 2020, 13, 4327, doi:10.3390/ma13194327.

31. Waseem, M.; Salah, B.; Habib, T.; Saleem, W.; Abas, M.; Khan, R.; Siddiqi, M.U.R. Multi-response optimization of tensile creep behavior of pla 3d printed parts using categorical response surface method-ology. Polymers 2020, 12, 2962.

32. Kamal, A.; Azfar, R.W.; Salah, B.; Saleem, W.; Abas, M.; Khan, R.; Pruncu, C.I. Quantitative analysis of sustainable use of construction materials for supply chain integration and construction industry perfor-mance through structural equation modeling (SEM). Sustainability 2021, 13, 522.

33. Markopoulos, A.; Karkalos, N.E.; Mia, M.; Pimenov, D.Y.; Gupta, M.K.; Hegab, H.; Khanna, N.; Balogun, V.A.; Sharma, S. Sustainability assessment, investigations, and modelling of slot milling characteristics in eco-benign machining of hardened steel. Metals 2020, 10, 1650, doi:10.3390/met10121650.

34. Pimenov, D.Y.; Abbas, A.T.; Gupta, M.K.; Erdakov, I.; Soliman, M.S.; El Rayes, M.M. Investigations of surface quality and energy consumption associated with costs and material removal rate during face milling of AISI 1045 steel. Int. J. Adv. Manuf. Technol. 2020, 107, 3511-3525, doi:10.1007/s00170-020-05236-7.

35. Abbas, A.T.; Pimenov, D.Y.; Erdakov, I.N.; Mikolajczyk, T.; Soliman, M.S.; El Rayes, M.M. Optimization of cutting conditions using artificial neural networks and the Edgeworth-Pareto method for $\mathrm{CNC}$ face-milling operations on high-strength grade- $\mathrm{H}$ steel. Int. J. Adv. Manuf. Technol. 2019, 105, 2151-2165, doi:10.1007/s00170-019-04327-4.

36. Muhammad, A.; Gupta, M.K.; Mikołajczyk, T.; Pimenov, D.Y.; Giasin, K. Effect of tool coating and cutting parameters on surface roughness and burr formation during micromilling of inconel 718. Metals 2021, 11, 167, doi:10.3390/met11010167.

37. Sen, B.; Hussain, S.A.I.; Gupta, A.D.; Gupta, M.K.; Pimenov, D.Y.; Mikołajczyk, T. Application of Type-2 Fuzzy AHP-ARAS for Selecting Opti-mal WEDM Parameters. Metals 2021, 11, 42, doi:10.3390/met11010042.

38. Saleem, W.; Salah, B.; Velay, X.; Ahmad, R.; Khan, R.; Pruncu, C.I. Numerical modeling and analysis of Ti6Al4V alloy chip for biomedical applications. Materials 2020, 13, 5236.

39. Abas, M.; Sayd, L.; Akhtar, R.; Khalid, Q.S.; Khan, A.M.; Pruncu, C.I. Optimization of machining pa-rameters of aluminum alloy 6026-T9 under MQL-assisted turning process. J. Mater. Res. Technol. 2020, 9, 10916-10940. 
40. Bhushan, R.K.; Kumar, S.; Das, S. Effect of machining parameters on surface roughness and tool wear for $7075 \mathrm{Al}$ alloy SiC composite. Int. J. Adv. Manuf. Technol. 2010, 50, 459-469, doi:10.1007/s00170-010-2529-2.

41. Pereira, R.B.D.; Leite, R.R.; Alvim, A.C.; de Paiva, A.P.; Balestrassi, P.P.; Ferreira, J.R.; Davim, J.P. Multivariate robust modeling and optimization of cutting forces of the helical milling process of the aluminum alloy Al 7075. Int. J. Adv. Manuf. Technol. 2017, 95, 2691-2715, doi:10.1007/s00170-017-1398-3.

42. Costa, D.M.D.; Belinato, G.; Brito, T.G.; Paiva, A.P.; Ferreira, J.R.; Balestrassi, P.P. Weighted principal component analysis combined with Taguchi's signal-to-noise ratio to the multiobjective optimization of dry end milling process: a comparative study. J. Braz. Soc. Mech. Sci. Eng. 2016, 39, 1663-1681, doi:10.1007/s40430-016-0614-7.

43. Tosun, N.; Huseyinoglu, M. Effect of MQL on surface roughness in milling of AA7075-T6. Mater. Manuf. Process. 2010, 25, 793798, doi:10.1080/10426910903496821.

44. Pillai, J.U.; Sanghrajka, I.; Shunmugavel, M.; Muthuramalingam, T.; Goldberg, M.; Littlefair, G. Opti-misation of multiple response characteristics on end milling of aluminium alloy using Taguchi-Grey relational approach. Measurement 2018, 124, 291298.

45. Arokiadass, R.; Palaniradja, K.; Alagumoorthi, N. Predictive modeling of surface roughness in end milling of $\mathrm{Al} / \mathrm{SiCp}$ metal matrix composite. Arch. Appl. Sci. Res. 2011, 3, 228-236.

46. Tang, Z.; Liu, Z.; Pan, Y.; Wan, Y.; Ai, X. The influence of tool flank wear on residual stresses induced by milling aluminum alloy. J. Mater. Process. Technol. 2009, 209, 4502-4508, doi:10.1016/j.jmatprotec.2008.10.034.

47. Kelly, J.; Cotterell, M. Minimal lubrication machining of aluminium alloys. J. Mater. Process. Technol. 2002, 120, 327-334, doi:10.1016/s0924-0136(01)01126-8.

48. Aluminium Alloy 5005-Properties, Applications, Fabrication, Machinability and Weldability. Available online: https://www.azom.com/article.aspx?ArticleID=4244,Austral Wright Metals-Ferrous,Non-Ferrous and High Performance Alloys. (accessed on August 27 2020).

49. Babu, M.N.; Anandan, V.; Muthukrishnan, N.; Santhanakumar, M. End milling of AISI 304 steel us-ing minimum quantity lubrication. Measurement 2019, 138, 681-689.

50. Mia, M.; Gupta, M.K.; Pruncu, C.I.; Sen, B.; Khan, A.M.; Jamil, M. Six sigma optimization of multi-ple machining characteristics in hard turning under dry, flood, MQL and solid lubrication. J. Prod. Syst. Manuf. Sci. 2020, 1, 6.

51. ISO. ISO 4287-1:1984 Surface Roughness - Terminology - Part 1: Surface and its Parameters; ISO: Geneva, Switzerland, 1984.

52. Kurt, H.I.; Oduncuoglu, M.; Yilmaz, N.F.; Ergul, E.; Asmatulu, R. A comparative study on the effect of welding parameters of austenitic stainless steels using artificial neural network and taguchi approaches with ANOVA analysis. Metals 2018, 8, 326, doi:10.3390/met8050326.

53. Abas, M.; Naeem, K.; Habib, T.; Khan, I.; Farooq, U.; Khalid, Q.S.; Rahman, K. Development of prediction model for conductive pattern lines generated through positive displacement microdispensing system using artifi-cial neural network. Arab. J. Sci. Eng. 2020, 1-14, doi.org/10.1007/s13369-020-05103-3

54. Jan, Q.M.U.; Habib, T.; Noor, S.; Abas, M.; Azim, S.; Yaseen, Q.M. Multi response optimization of in-jection moulding process parameters of polystyrene and polypropylene to minimize surface roughness and shrinkage's using integrated approach of $\mathrm{S} / \mathrm{N}$ ratio and composite desirability function. Cogent Eng. 2020, 7, doi:10.1080/23311916.2020.1781424.

55. Costa, N.R.; Lourenco, J.C.; Pereira, Z.L. Desirability function approach: A review and performance evaluation in adverse conditions. Chemom. Intell. Lab. Syst. 2011, 107, 234-244, doi:10.1016/j.chemolab.2011.04.004.

56. Pignatiello, J.J. An Overview of the strategy and tactics of taguchi. IIE Trans. 1988, 20, 247-254, doi:10.1080/07408178808966177.

57. Derringer, G.; Suich, R. Simultaneous optimization of several response variables. J. Qual. Technol. 1980, 12, 214-219, doi:10.1080/00224065.1980.11980968.

58. Chate, G.R.; Patel, G.C.M.; Kulkarni, R.M.; Vernekar, P.; Deshpande, A.S.; Parappagoudar, M. Study of the effect of nano-silica particles on resin-bonded moulding sand properties and quality of casting. Silicon 2018, 10, 1921-1936, doi:10.1007/s12633-0179705-z.

59. Javed, S.A.; Mahmoudi, A.; Khan, A.M.; Javed, S.; Liu, S. A critical review: Shape optimization of welded plate heat exchangers based on grey correlation theory. Appl. Therm. Eng. 2018, 144, 593-599, doi:10.1016/j.applthermaleng.2018.08.086.

60. Lotfi, F.H.; Fallahnejad, R. Imprecise Shannon's entropy and multi attribute decision making. Entropy 2010, 12, 53-62, doi:10.3390/e12010053.

61. Diakoulaki, D.; Mavrotas, G.; Papayannakis, L. Determining objective weights in multiple criteria problems: The critic method. Comput. Oper. Res. 1995, 22, 763-770, doi:10.1016/0305-0548(94)00059-h.

62. Qazi, M.I.; Akhtar, R.; Abas, M.; Khalid, Q.S.; Babar, A.R.; Pruncu, C. An integrated approach of GRA coupled with principal component analysis for multi-optimization of shielded metal arc welding (SMAW) process. Materials 2020, 13, 3457, doi:10.3390/ma13163457.

63. Sonawane, S.A.; Kulkarni, M. Optimization of machining parameters of WEDM for Nimonic-75 alloy using principal component analysis integrated with Taguchi method. J. King Saud Univ. Eng. Sci. 2018, 30, 250-258, doi:10.1016/j.jksues.2018.04.001.

64. Lee, W.J.; Mendis, G.P.; Triebe, M.J.; Sutherland, J.W. Monitoring of a machining process using kernel principal component analysis and kernel density estimation. J. Intell. Manuf. 2019, 31, 1175-1189, doi:10.1007/s10845-019-01504-w.

65. Das, R.; Ball, A.K.; Roy, S.S. Application of PCA-based hybrid methodologies for parameter optimi-zation of E-jet based microfabrication process: a comparative study. J. Braz. Soc. Mech. Sci. Eng. 2018, 40, 45.

66. Jones, B.; Montgomery, D.C. Design of Experiments: A Modern Approach; Wiley: Hoboken, NJ, USA, 2019. 
67. Stephens, M.A. EDF statistics for goodness of fit and some comparisons. J. Am. Stat. Assoc. 1974, 69, 730, doi:10.2307/2286009.

68. Sreejith, P. Machining of 6061 aluminium alloy with MQL, dry and flooded lubricant conditions. Mater. Lett. 2008, 62, 276-278, doi:10.1016/j.matlet.2007.05.019.

69. Roy, P.; Sarangi, S.; Ghosh, A.; Chattopadhyay, A. Machinability study of pure aluminium and Al-12\% Si alloys against uncoated and coated carbide inserts. Int. J. Refract. Met. Hard Mater. 2009, 27, 535-544, doi:10.1016/j.ijrmhm.2008.04.008.

70. Astakhov, V.P. Tribology of Metal Cutting; Elsevier: Amsterdam, The Netherlands, 2006. 